\title{
Standby Rates for Combined Heat and Power Systems
}

Economic Analysis and Recommendations for Five States

\author{
Authors \\ James Selecky \\ Kathryn Iverson \\ Ali Al-Jabir
}

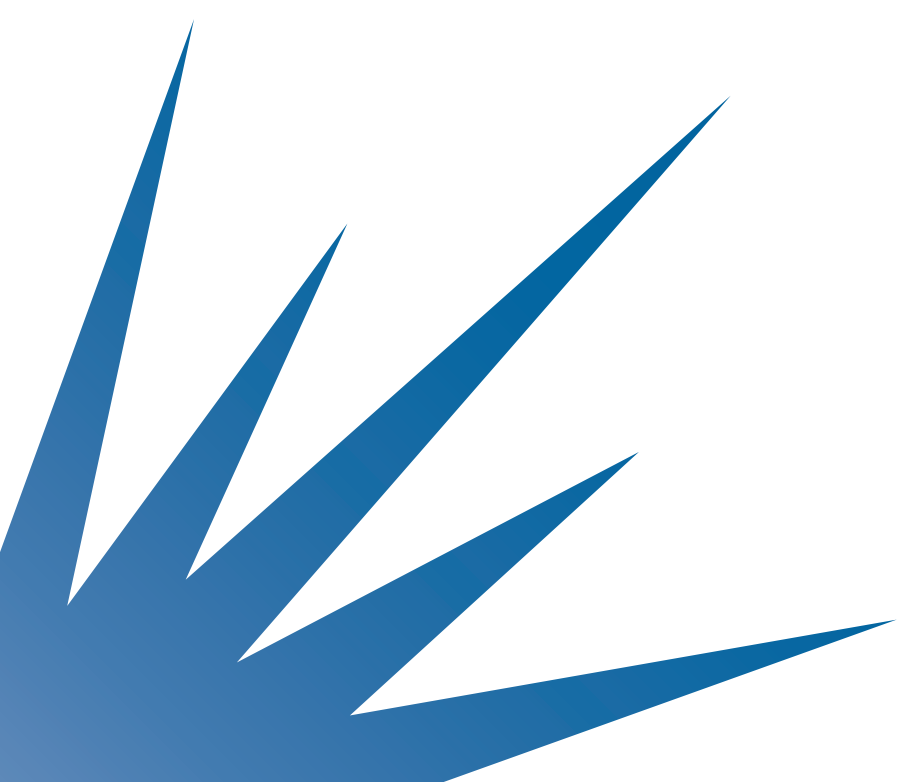




\title{
Standby Rates for Combined Heat and Power Systems:
} Economic Analysis and Recommendations for Five States

\author{
Prepared by Brubaker \& Associates, Inc. \\ and the Regulatory Assistance Project \\ for Oak Ridge National Laboratory
}

Lead authors: James Selecky, Kathryn Iverson, and Ali Al-Jabir, Brubaker \& Associates, Inc.

Project manager, contributor, and technical editor: Lisa Schwartz, Regulatory Assistance Project

Final editor: Richard Sedano, Regulatory Assistance Project

Oak Ridge National Laboratory Technical Project Officer: Patricia Garland

Special thanks to the Public Utility Commissions of Arkansas, Colorado, New Jersey, Ohio, and Utah for participating in this project. Additional valuable comments and reviews were provided by Cliff Haefke, Bruce Hedman, Katrina Pielli, Patti Garland, and Michael Starke. Camille Kadoch, John Gerhard and Dave Lamont of RAP contributed important pieces to the final report.

This report was prepared as an account of work sponsored by an agency of the United States Government. Neither the United States Government nor any agency thereof, nor any of their employees, makes any warranty, express or implied, or assumes any legal liability or responsibility for the accuracy, completeness, or usefulness of any information, apparatus, product, or process disclosed, or represents that its use would not infringe privately owned rights. Reference herein to any specific commercial product, process, or service by trade name, trademark, manufacturer, or otherwise, does not necessarily constitute or imply its endorsement, recommendation, or favoring by the United States Government or any agency thereof. The views and opinions of authors expressed herein do not necessarily state or reflect those of the United States Government or any agency thereof.

Electronic copies of this paper and other RAP publications can be found on our website at www.raponline.org.

To be added to our distribution list, please send relevant contact information to info@raponline.org. 


\section{Table Of Contents}

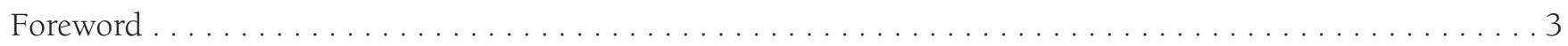

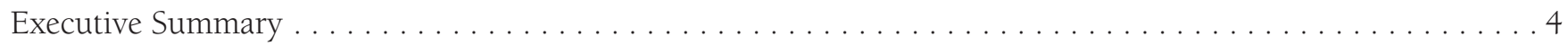

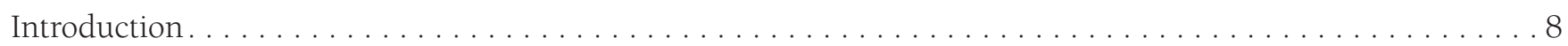

Chapter 1. Best Practices in Standby Rate Design . . . . . . . . . . . . . . . . . . . . 11

Chapter 2. Economic Analysis for Study. . . . . . . . . . . . . . . . . . . . . . . . . . . . . 15

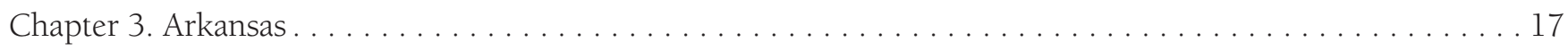

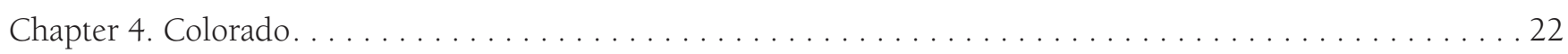

Chapter 5. New Jersey . . . . . . . . . . . . . . . . . . . . . . . . . . . . . . . . . 26

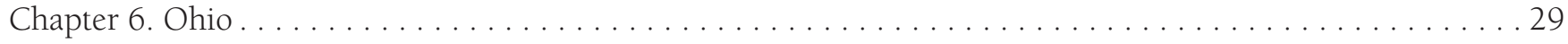

Chapter 7. Utah . . . . . . . . . . . . . . . . . . . . . . . . . . . . . . . . 35

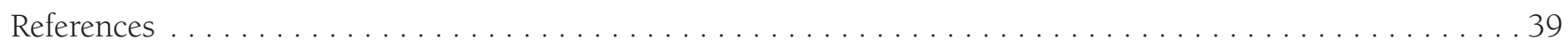

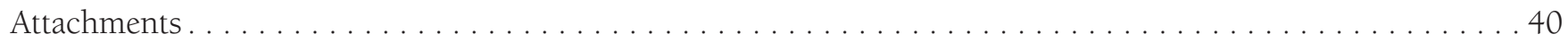

\section{Table of Figures}

Figure 1: Illustration of Self-Generating Customers' Purchase Power Requirements. . . . . . . . . . . . . 8

\section{Table of Tables}

Table 1: Selected Utilities and State Regulators . . . . . . . . . . . . . . . . . . . . . . 9

Table 2: Illustrative Coincidence Factors . . . . . . . . . . . . . . . . . . . . . . . . . . . . . 10

Table 3: Impact of Coincidence Factor on Demand Charges . . . . . . . . . . . . . . . . . . . . . . . . . . 12 


\section{List of Acronyms and Abbreviations}

$\begin{array}{llll}\text { AG } & \text { Average Generation } & \text { LPS } & \text { Large Power Service } \\ \text { BAI } & \text { Brubaker \& Associates, Inc. } & \text { MM } & \text { Maximum Monthly } \\ \text { BD } & \text { Billing Demand } & \text { NCP } & \text { Non Coincident Peak Demand } \\ \text { CD } & \text { Contract Demand } & \text { OAD-SBS } & \text { Open Access Distribution Standby Service } \\ \text { CHP } & \text { Combined Heat and Power } & \text { OATT } & \text { Open Access Transmission Tariff } \\ \text { CP } & \text { Coincident Peak Demand } & \text { ORNL } & \text { Oak Ridge National Laboratory } \\ \text { CRES } & \text { Certified Retail Electric Service } & \text { PSCo } & \text { Public Service Company of Colorado } \\ \text { DOE } & \text { (U.S.) Department of Energy } & \text { PURPA } & \text { Public Utility Regulatory Policies Act } \\ \text { DR } & \text { Demand Rate } & \text { RAP } & \text { Regulatory Assistance Project } \\ \text { EAI } & \text { Entergy Arkansas, Inc. } & \text { RMP } & \text { Rocky Mountain Power } \\ \text { EV } & \text { Expected Value } & \text { SBS } & \text { Standby Service } \\ \text { FERC } & \text { Federal Energy Regulatory Commission } & \text { SR } & \text { Standby Rate } \\ \text { FOR } & \text { Forced Outage Rate } & \text { SSO } & \text { Standard Service Offer } \\ \text { GW } & \text { Gigawatts } & \text { SSR } & \text { Standby Service Rider } \\ \text { kW } & \text { Kilowatts } & \text { STB } & \text { Standby Service Rider } \\ \text { LGS } & \text { Large General Service } & \text { VAR } & \text { Voltage Adjustment Rider }\end{array}$




\section{Foreword}

I

mprovements in technology, low natural gas prices, and more flexible and positive attitudes in government and utilities are making distributed generation more viable. With more distributed generation, notably combined heat and power, comes an increase in the importance of standby rates, the cost of services utilities provide when customer generation is not operating or is insufficient to meet full load.

This work digs into existing utility standby tariffs in five states. It uses these existing rates and terms to showcase practices that demonstrate a sound application of regulatory principles and ones that do not.

In cases where we find deficiencies, it is not to embarrass, but rather to call attention to opportunities for improving a set of rates that are often governed by the outmoded idea that distributed generation is rare and inherently risky to utility operations and customers. Also, these rates do not get a lot of attention and likely are due for reassessment soon in many jurisdictions.

Trends show that distributed generation is not rare anymore and that old ideas about risk have been replaced by utility operator confidence in anticipated performance, which stems from interconnection agreements and probabilistic assessments. Rates and charges that may have been set roughly can be modified to apply better matching of utility costs with the services customers' use. The context for this work, then, is part of a trend to a more customer-focused utility sector that not only looks to provide good service, but looks to the consumer as a resource.

We find many areas for improvement in standby rates. Will utilities and their regulators take steps to consider and execute these changes? Time will tell, but with technology driving applications and deployment, utilities and their regulators will be hard-pressed to do any less than steward this progress.

\author{
Richard Sedano \\ Director, US Programs \\ Regulatory Assistance Project
}




\section{Executive Summary}

tandby, or partial requirements, service is the set of retail electric products for customers who operate onsite, non-emergency generation. Utility standby rates cover some or all of the following services:

- Backup power during an unplanned generator outage;

- Maintenance power during scheduled generator service for routine maintenance and repairs;

- Supplemental power for customers whose onsite generation under normal operation does not meet all of their energy needs, typically provided under the full requirements tariff for the customer's rate class;

- Economic replacement power when it costs less than onsite generation; and

- Delivery associated with these energy services.

This paper presents the results of an analytical assessment of the rates, terms, and conditions for standby service in five states: Arkansas, Colorado, New Jersey, Ohio, and Utah. Specifically the study evaluated the efficacy of standby tariffs for combined heat and power (CHP) applications.

This paper sets forth options to improve the tariffs analyzed and the estimated economic impact of the suggested tariff improvements for a selected set of proxy utility customers who have CHP systems. Although the study and recommendations targeted participating states, the analytical methods, spreadsheets, and recommendations can be adapted for use by other jurisdictions. ${ }^{1}$

\section{Selection of States and Tariffs for Analysis}

The Regulatory Assistance Project (RAP) identified candidate states for the project considering geographic diversity, representation of states with restructured electricity markets as well as those that remain vertically integrated, and the jurisdictions' interest in reviewing standby tariffs.
To keep the project manageable, RAP and Brubaker $\&$ Associates, Inc. (BAI) worked with state regulatory commission staff to select a single investor-owned utility for tariff evaluation:

\begin{tabular}{|c|c|c|}
\hline State & Utility & Tariff(s) \\
\hline Arkansas & Entergy Arkansas, Inc. & Standby Service Rider \\
\hline Colorado & $\begin{array}{l}\text { Public Service } \\
\text { Company of Colorado }\end{array}$ & $\begin{array}{l}\text { Schedule PST } \\
\text { Schedule TST }\end{array}$ \\
\hline New Jersey & $\begin{array}{l}\text { Jersey Central Power } \\
\& \text { Light Company }\end{array}$ & Rider STB \\
\hline Ohio & $\begin{array}{l}\text { AEP-Ohio Power } \\
\text { Company }\end{array}$ & $\begin{array}{l}\text { Schedule SBS } \\
\text { Schedule OAD-SBS }\end{array}$ \\
\hline Utah & $\begin{array}{l}\text { Rocky Mountain } \\
\text { Power }\end{array}$ & Schedule 31 \\
\hline
\end{tabular}

\section{Coordination With State Regulatory Commissions}

RAP and BAI presented the results of the economic analysis and recommendations to regulatory commission staff and provided an opportunity for review and comment. In some cases, public workshops were held with commissioners, utility representatives, affected customer groups, and other stakeholders. This interactive process informed and enhanced the development of the analyses and recommendations presented in this paper.

\section{Description of Analytical Methods}

BAI estimated economic impacts of the standby tariffs using an Excel spreadsheet model customized for each tariff analyzed. The model calculates standby service costs under the currently effective standby rates. When practical, models were also used to calculate the costs resulting from the tariff modifications.

1 For state specific attachments and a link to the Excel model for each state, please go to: http://www.raponline. org/featured-work/standby-rates-for-CHP 


\section{Standby Rate Tariff Structures}

While standby rates vary widely, they typically include the following:

- A capacity reservation charge is a charge to compensate the utility for the capacity that the utility must have available to serve a customer during an unscheduled outage of the customers own generation unit.

- Capacity and energy charges for the actual electricity supplied to a customer during an unscheduled outage of the customer's own generation unit.

- A maintenance capacity charge for the capacity supplied by the utility during a scheduled outage of the customer's own generation unit, and,

- facility charges to compensate the utility for any dedicated distribution costs.

\section{Summary of Best Practices in Standby Rate Design}

Based on the experience of RAP and BAI in the area of standby rate design, explained in Chapter 1 , the following are best practices for consideration in the development of standby rates:

\section{Allocation of Utility Costs}

- Generation, transmission, and distribution charges should be unbundled in order to provide transparency to customers and enable appropriate and cost-based standby rate design.

- Supplemental power charges should be based on charges in the applicable full requirements tariff.

- Generation reservation demand charges should be based on the utility's cost and the forced outage rate of customers' generators on the utility's system.

\section{Judgments Based on Statistical Method}

- Standby rate design should not assume that all forced outages of on-site generators occur simultaneously, or at the time of the utility system peak.

- Transmission and higher-voltage distribution demand charges should be designed in a manner that recognizes load diversity.

- Standby rate design should assume that maintenance outages of on-site generators would be coordinated with the utility and scheduled during periods when system generation requirements are low.

\section{Value of Customer Choice and Incentives}

- Daily maintenance demand charges should be discounted relative to daily backup demand charges to recognize the scheduling of maintenance service during periods when the utility generation requirements are low.

- Customers should have the option to purchase all or some portion of their standby service on an interruptible basis and thereby avoid generation reservation demand charges.

- Pro-rated, daily, as-used demand charges for backup power and shared transmission and distribution facilities should be used to provide an incentive for generator reliability.

- Customers should be able to procure standby service from competitive power providers at prevailing market prices, where available.

\section{Recommendations for Standby Tariff Modifications}

Based on RAP's and BAI's experience in standby rate design and the analyses conducted by the study's authors, the following are potential modifications to the rate designs, terms, and conditions of the standby tariffs analyzed. Descriptions of the current tariffs appear in the corresponding chapters.

\section{Arkansas - Entergy Arkansas Inc.'s (EAI) Standby Service Rider SSR (Chapter 3)}

- The reservation demand charge should be unbundled into generation, transmission, and distribution components.

- The unbundled generation component of the reservation demand charge for standby service should be set such that it is equivalent to the best FOR exhibited by any generating unit on EAI's system.

- The reservation demand charge should be differentiated by season.

- The daily backup and maintenance demand charges should apply only during on-peak periods.

- The daily backup and maintenance energy charges should be differentiated on a time of-use basis.

- Customer-generators should have the option to buy backup power from the market through the utility and avoid monthly reservation charges for standby generation service.

- The Non-Reserve Service feature of Rider SSR should be modified to facilitate the provision of interruptible standby service. 
- Standby charges for shared transmission and distribution facilities should reflect load diversity.

- Standby charges should be concise and easily understandable. Customers who may consider installing a CHP system may have a difficult time understanding all of the charges they may pay under various circumstances with the standby tariffs and riders EAI has in place today.

- The standby tariffs should specify the circumstances under which a special contract may be warranted.

\section{Colorado - Public Service Company of Colorado (PSCo) Schedules PST and TST (Chapter 4)}

- The Grace Energy Hours provision should be eliminated and replaced with a lower generation reservation fee coupled with a daily demand charge.

- The generation reservation fee should reflect the best FOR exhibited by any customer's generating unit on PSCo's system.

- Daily demand charges should be implemented to provide incentives to improve the performance of self-generating units.

- The standby backup demand charges for generation, transmission, and certain distribution costs should apply only during on-peak hours.

- Customers should have the option to buy backup power at prevailing market prices through the utility if available and thereby avoid standby generation charges.

- Customer-generators should have the option to provide the utility with a load reduction plan that demonstrates their ability to reduce a specified amount of load (in kilowatts $[\mathrm{kW}]$ ) within a required timeframe and avoid standby generation charges.

- Standby rates for shared distribution facilities should reflect load diversity.

- The generation and transmission cost components of the reservation fee should be unbundled.

\section{New Jersey - Jersey Central Power \& Light} Company Standby Service Rider STB (Chapter 5)

- Scheduled maintenance hours should be allowed for all standby customers. The tariff states that customers who commence service after February 25, 1993 are not allowed to schedule maintenance for their generating units.

- Standby service should be available to all customergenerators regardless of the availability factor of their generating unit.

- Standby tariffs should be concise and easily understandable. Customers may have difficulty understanding this tariff because of the different types of demand measurements and the manner in which charges are assessed.

- Standby charges for shared distribution facilities should reflect load diversity. ${ }^{2}$

\section{Ohio - AEP-Ohio Power Company's Schedules SBS and OAD-SBS (Chapter 6)}

- Generation reservation charges should reflect the best FOR exhibited by any generating unit on the system.

- Daily demand charges should be developed to provide incentives to improve generator performance.

- Customers should have the option to buy backup power from the market. ${ }^{3}$

- Charges for distribution facilities should reflect load diversity.

- The distribution component of the reservation charge should be adjusted to include only the cost associated with dedicated distribution facilities. The tariffs should be concise and easily understandable.

- The tariffs should specify that special circumstances may warrant a special contract.

2 Rider STB may already recognize load diversity. The standby distribution charges are substantially below the full requirements service distribution charges.

3 By the end of 2015, all customers of AEP-Ohio Power Company will be able to choose an alternative electricity supplier. 
Utah - Rocky Mountain Power Schedule 31 and

Schedule 33 (Chapter 7)

- The on-peak backup charges should be calculated and stated on a seasonal basis.

- The generation reserve charge should be modified to reflect the performance of the best generating unit.

- The shared transmission and distribution standby demand charges should be adjusted to reflect load diversity.

- The distribution component of the reservation charge should be adjusted to include only the cost associated with dedicated distribution facilities.
- Customers should have the option to buy backup power from the market through the utility and thereby avoid backup charges for standby power.

- Customers should have the option to provide the utility with a load reduction plan that demonstrates their ability to reduce a specified amount of load $(\mathrm{kW})$ within a required timeframe to mitigate all, or a portion of, the backup demand charges.

- Customers should be allowed to take a total of up to 30 days of maintenance power per year without the current constraint of taking this service only twice during the year. 


\section{Introduction}

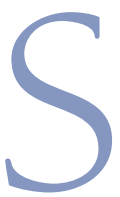
tandby, or partial requirements, service is the set of retail electric products for customers who have onsite, non-emergency generation, such as combined heat and power (CHP). By simultaneously producing useful electric and thermal energy from a single fuel source at a customer's site, CHP enhances energy efficiency, improves environmental quality, and makes businesses more competitive.

Utility standby rates cover some or all of the following standby services (see Figure 1): ${ }^{4}$

- Backup power during an unplanned generator outage;

- Maintenance power during scheduled generator service for routine maintenance and repairs;

- Supplemental power for customers whose onsite generation under normal operation does not meet all of their energy needs, typically provided under the full requirements tariff for the customer's rate class;

- Economic replacement power when utility power costs less than onsite CHP generation; and

- Delivery associated with these energy services.

On August 30, 2012 President Obama issued an Executive Order ${ }^{6}$ that sets a goal of 40 gigawatts (GW) of new, cost-effective industrial CHP in the United States by 2020, a 50-percent increase from today. Meeting this goal would save energy users an estimated $\$ 10$ billion

\section{Figure 1}

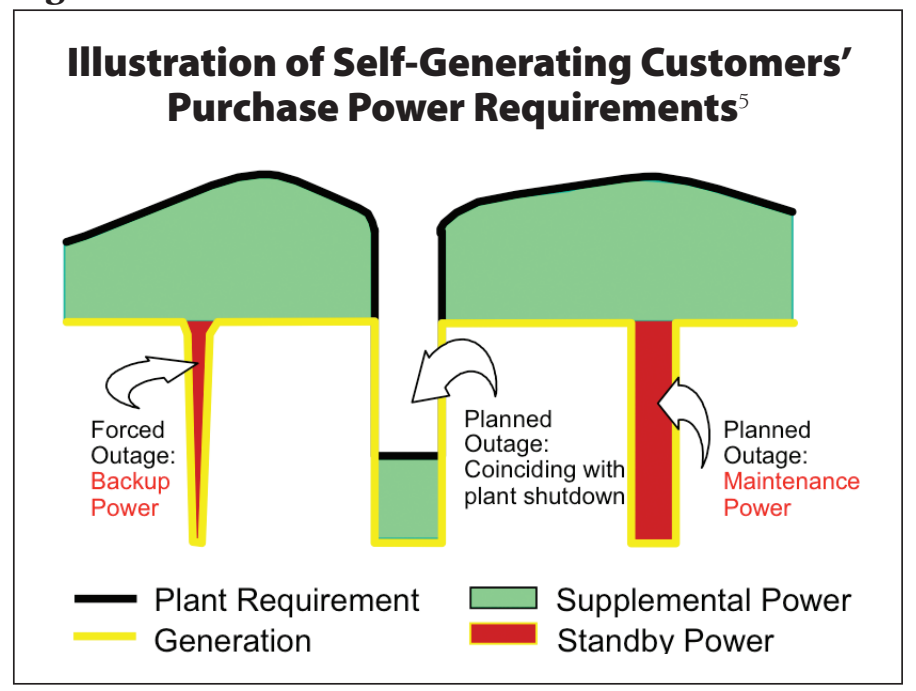

per year, result in $\$ 40$ to $\$ 80$ billion in new capital investment in manufacturing and other facilities, create American jobs, and reduce emissions equivalent to 25 million cars.

Standby rates are an important factor in determining the relative economics of $\mathrm{CHP}$ applications, compared to taking full requirements service from an electric utility or alternative electricity supplier. Charges or terms and conditions of a standby tariff that would result in excessive costs for standby service would unnecessarily discourage CHP development, an inherently more energyefficient technology than taking traditional utility or alternate supplier power.

RAP and others have documented best practices in standby rate design and utility tariffs that exemplify these principles. ${ }^{7,8}$ Building on this foundation, RAP recruited state regulatory commissions to work with a technical consultant to review standby tariffs in place today against these approaches and take preliminary steps to consider tariff improvements to facilitate adoption of CHP systems.

With funding from the U.S. Department of Energy (DOE) and under contract to Oak Ridge National Laboratory (ORNL), RAP hired Brubaker \& Associates, Inc. (BAI) to perform the economic analysis of standby tariffs in five states, work with RAP to recommend possible tariff modifications that could improve their efficacy for CHP applications, and quantify the potential economic impact of the recommended improvements for proxy industrial and commercial customers.

RAP and BAI conducted a preliminary assessment of standby rates in selected states to identify tariffs that

4 In restructured states, the utility may provide only delivery services and provider-of-last-resort energy service.

5 Source: Brubaker \& Associates.

6 The White House, Office of the Press Secretary, 2012.

7 See, in particular, Weston, et al., 2009. For examples of current utility standby practices, see Stanton, 2012.

8 Johnston, et al., 2008. 
Table 1

\section{Selected Utilities and State Regulators}

Utility

Ohio Power Company (AEP)

Entergy Arkansas, Inc.

Rocky Mountain Power Company (PacifiCorp)

Public Service Company of Colorado

Jersey Central Power \& Light Company (FirstEnergy)
Regulatory Jurisdiction

Public Utilities Commission of Ohio

Arkansas Public Service Commission

Public Service Commission of Utah

Colorado Public Utilities Commission

New Jersey Board of Public Utilities present opportunities for improvement that would make them more attractive for CHP applications, while adhering to ratemaking principles. To some extent, the selection process was random. However because cooperation was needed from the state regulatory agencies, consideration was given to states where there was a past working relationship with RAP. In cooperation with regulatory utility commission staff, one utility per state was selected for detailed tariff review and analysis (see Table 1).

The tariffs were first analyzed at a conceptual level to understand each component and the manner in which these components interact with one another, associated tariff riders, and applicable full requirements tariffs. The project team then identified specific areas where tariff modifications could be made to reduce hurdles to installation of cost-effective CHP systems. BAI developed a Microsoft Excel model for each state to quantify the economic impact of the tariffs currently in place and evaluate the proposed tariff enhancements. The model runs use only publicly available information: (1) the rates, terms, and conditions in the relevant tariffs, and (2) customer usage and load characteristics, standby power needs, and generator sizes and types developed by each state project team to represent industrial and commercial customers with promise for adopting CHP.

This report is organized into three major sections:

- Best Practices in Standby Rate Design sets forth basic concepts for understanding the economics of standby rate design, discusses the economic and policy criteria that establish the foundation for good standby rate designs, and describes best practices in standby rate design.

- Economic Analysis for Study discusses the process for the selection of representative customergenerators for analysis, describes the process used to identify potential improvements and enhancements to the standby tariffs analyzed in the study, and discusses the modeling methods and assumptions used to quantify the potential economic impact of the proposed tariff improvements.

- State-Specific Standby Rate Analyses describe the standby tariffs examined, assess the efficacy of the tariffs for CHP applications, recommend improvements to the tariffs, and present the economic analysis.

Appendices to this document (available online) include the standby power tariffs surveyed, detailed results of economic analyses performed for this study, work papers supporting the analysis and recommendations, and a list of resources for additional information on standby rates.

\section{Definition of Key Concepts}

Following are central rate design concepts important for understanding the economic rationale behind the design of standby rates.

Backup power is electric capacity and energy supplied by an electric utility during an unscheduled outage of the customer's on-site generation. Thus, backup power is supplied by the utility on a random basis to replace capacity and energy ordinarily generated by a customer's own generation equipment.

Capacity/demand charges are charges based on a customer's highest usage in a one hour or shorter interval during a billing cycle.

Energy charges are the part of the charge for electric service based upon the electric energy consumed or billed.

Maintenance power is electric capacity and energy supplied by an electric utility during scheduled outages of the customer's on-site generation. This type of power is provided on a prearranged, scheduled basis to allow the customer to take its equipment out of service for routine inspections and preventive maintenance. 
Demand Ratchets: Some tariffs set the billing demand at the higher of (1) the current month's measured demand or (2) a fraction (typically 60 or 90 percent, but sometimes as much as 100 percent) of the customer's highest measured demand in the previous year or in the past peak season. This type of pricing is referred to as a "demand ratchet."

Reserve Capacity/Reserve Margin/Reserves are the amount of capacity that a system must be able to supply, beyond what is required to meet demand, in order to assure reliability when one or more generating units or transmission lines are out of service. Traditionally a 15-20 percent reserve capacity was thought to be needed for good reliability. In recent years, the accepted value in some areas has declined to 10 percent.

Supplemental power is electric capacity and energy supplied by an electric utility that is regularly used by a self-generating customer in addition to capacity and energy from on-site generation. Because this service usually is available "around the clock" and on a "firm" basis, supplemental power is the same as full requirements service for non-generating customers. Supplemental power is typically charged at the otherwise applicable full-requirements tariff rates.

Coincidence factor is the ratio of a customer's coincident peak demand (CP) to its non coincident peak demand (NCP), or billing demand. A customer's CP is the demand imposed by the customer at the time of the utility system's maximum demand. The customer's NCP is the customer's maximum demand recorded at any time during a specified time interval. $\mathrm{CP}$ and NCP may be measured on a monthly or annual basis. Table 2 illustrates how coincidence factor is determined.

Both customers, FR1 and FR2, purchase full
Table 2

\section{Illustrative Coincidence Factors}

$\begin{array}{lccc}\text { Customer } & \begin{array}{c}\text { Coincident } \\ \text { Demand } \\ (\mathbf{k W})\end{array} & \begin{array}{c}\text { Billing or } \\ \text { Non-Coincident } \\ \text { Demand (kW) }\end{array} & \begin{array}{c}\text { Coincidence } \\ \text { Factor* }\end{array} \\ \text { FR1 } & 1,000 & 2,000 & 50 \% \\ \text { FR2 } & 1,000 & 1,250 & 80 \% \\ * \text { Column } 1 \div \text { Column } 2 & & \end{array}$

requirements service and impose a 1,000-kW CP demand on the system. Customer FRl has a NCP demand of 2,000 kW, while the NCP demand of Customer FR2 is $1,250 \mathrm{~kW}$. Thus, Customer FR1 has a 50-percent coincidence factor $(1,000 \mathrm{~kW} / 2,000 \mathrm{~kW})$, while Customer FR2 has an 80-percent coincidence factor (1,000 kW/1,250 kW).

The Forced Outage Rate (FOR) of a generating unit for a given time interval is defined as the number of hours that the unit is forced out of service for emergency reasons, divided by the total number of hours that the generating unit is available for service during that time interval plus the number of hours that the generating unit experiences a forced outage. The FOR of a generating unit measures the probability that the unit will not be available for service when required. Essentially the FOR provides an indication of the percentage of time that a generating unit is forced out of service for emergency reasons. The FOR is a measure of a generating unit's reliability.

9 Lazar, 2013 


\section{Chapter 1. Best Practices in Standby Rate Design}

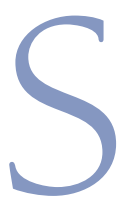

tandby rates are typically designed to recover the fully allocated embedded costs that the utility incurs to provide standby service to selfgenerating customers and, for investor-owned utilities, a reasonable rate of return established by the applicable state regulatory commission. The federal Public Utility Regulatory Policies Act (PURPA) established the fundamental cost of service and legal principles that govern the design of standby rates. These principles have been implemented on a state-by-state basis through state regulatory commission rules and rate orders that establish utility-specific tariffs of general applicability for the provision of standby power.

In competitive electricity markets, market prices determine the charges for standby service from electricity suppliers. Generally the electricity cost of backup power (distinct from the delivery ${ }^{10}$ costs) is determined by the market price at the time of the customer-generator's outage.

\section{Economic and Policy Principles Governing the Design of Standby Rates}

In general, state regulatory utility commissions require that standby rates be based on the same cost-of-service principles that are applied to the utility's full requirements customers. These rate design principles are consistent with the requirements of PURPA that: ${ }^{11}$

Rates for sales shall be just and reasonable and in the public interest and shall not discriminate against any qualifying facility in comparison to rates for sales to other customers served by the electric utility.

$$
* * * *
$$

Rates for sales which are based on accurate data and consistent with system-wide costing principles shall not be considered to discriminate against any qualifying facility to the extent that such rates apply to the utility's other customers with similar load or other cost-related characteristics.

In other words, a self-generating customer should not pay more for purchased electricity from the utility than other customers having similar load and other cost- related characteristics (size, delivery voltage, and so on).

A critical issue in designing cost-based standby rates is determining the appropriate level of generation reserve capacity that a utility must carry to provide standby service to self-generators on its system. The required level of utility reserves to support standby service is a function of generator resource reliability. A self-generator having greater reliability than utility controlled resources may require reserves lower than the utility average. On the other hand, a self-generator with below-average reliability could require above-average reserves. A precise determination can only be made through longrun observed performance of the facilities in question. Methods to design prices for standby service, standby generation reservation, and daily as-used demand will be summarized in the rest of the paper. These rates and methods are also demonstrated in the online companion Excel spreadsheets with this report.

\section{Impact of Coincidence Factor on Standby Power Requirements}

Standby customers have different load characteristics than non-generating (i.e., full-requirements) customers. Whereas full-requirements customers typically impose load on the utility system 365 days a year, a reliable standby customer requires backup power only on a handful of days during random generator outages.

The effect is that a utility supplying standby power will not have to plan as much reserve capacity to serve self-generating customers as it does for full-requirements customers. There are two reasons for this. First, not all customer-generators will require standby power at the same time. Second, it is highly unlikely that such purchases will coincide with the system peak. A customer having a low coincidence factor should pay less per $\mathrm{kW}$ of non coincident peak, or billing demand, than another

10 "Delivery" as used in this paper is synonymous with "transmission and distribution."

1118 C.F.R \& 292.305 (1)(i)(ii) and (2). 
Table 3

Impact of Coincidence Factor on Demand Charges

\begin{tabular}{|c|c|c|c|c|c|}
\hline Customer & $\begin{array}{c}1 . \\
\text { Coincident } \\
\text { Demand } \\
(C P \text { kW })\end{array}$ & $\begin{array}{c}2 . \\
\text { Billing } \\
\text { Demand } \\
\text { (BD kW) }\end{array}$ & $\begin{array}{c}3 . \\
\text { Coincidence } \\
\text { Factor }\end{array}$ & $\begin{array}{c}4 . \\
\text { Demand } \\
\text { Costs* }\end{array}$ & $\begin{array}{c}5 . \\
\text { Demand } \\
\text { Charge** } \\
(\$ / k W)\end{array}$ \\
\hline FR1 & 1,000 & 2,000 & $50 \%$ & $\$ 10,000$ & $\$ 5.00$ \\
\hline FR2 & 1,000 & 1,250 & $80 \%$ & $\$ 10,000$ & $\$ 8.00$ \\
\hline Standby & 1,000 & 20,000 & $5 \%$ & $\$ 10,000$ & $\$ 0.50$ \\
\hline
\end{tabular}

customer having a higher coincidence factor. Generally the utility system is large enough to accommodate the needs of its self-generating customers.

Coincidence factor is relevant in designing rates because most electric utilities bill for demand on a noncoincident basis. A customer having a higher coincidence factor will impose higher demand-related costs per $\mathrm{kW}$ of billing demand than a customer having a lower coincidence factor. Table 3 illustrates this point.

All three customers illustrated in Table 3 impose the same coincident demand on the utility, and total demand costs are allocated relative to coincident demand. Customers FR1 and FR2 purchase full requirements service and have a coincidence factor of 50 percent and 80 percent, respectively. This is typical of a utility's full requirements customers. The standby customer, by contrast, has a five-percent coincidence factor. This may be reflective of backup power requirements over time. In some years, a forced outage may occur coincident with the peak. In other years, it may not.

All other things being equal, the lower the coincidence factor, the lower the per-unit standby demand charge needed. This is because there are more billing units (Column 2) over which to spread the allocated demandrelated costs (Column 4) for backup power than for full-requirements service. Whereas a $\$ 5 / \mathrm{kW}$ or $\$ 8 / \mathrm{kW}$ demand charge would be appropriate for full requirements customers, a reliable standby customer should be charged only a fraction of these amounts for standby power, or $\$ 0.50 / \mathrm{kW}$, based on the previous example.

Backup and maintenance service do not have the same coincidence with the system peak as full requirements utility service. Whether backup power service is more or less coincident than full-requirements utility service depends on the reliability of the customer's generating unit. Maintenance power, as typically defined by utility tariffs, would only be provided during times of the year when the utility has adequate generating resources available. It could therefore be argued that properly scheduled maintenance power would have a coincidence factor near zero. Forced outages, by contrast, are more random in nature.

These distinctions between the nature of backup and maintenance service have important rate design implications. Specifically, the rates for backup power service should reflect the fact that the utility is providing only the reserve capacity. Properly scheduled maintenance power service rates should reflect both the lower cost and the off-peak nature of this service. It is a lower cost service than firm backup power because utilities generally require maintenance service to be scheduled in advance, and service may be refused if adequate resources are not available to accommodate a planned outage. This lower quality of service should be reflected in the form of a price discount for maintenance power relative to backup power service.

PURPA recognizes that backup and maintenance services are different from regular utility service. The rules state: ${ }^{12}$

Rates for sales of backup and maintenance power. The rate for sales of backup power or maintenance power:

(1) shall not be based upon an assumption (unless supported by factual data) that forced outages or other reductions in electric output by all qualifying facilities on an electric utility's system will occur simultaneously, or during the system peak, or both; and

(2) shall take into account the extent to which scheduled outages of the qualifying facilities can be usefully coordinated with scheduled outages of the utility's facilities.

\section{Generator Reliability and Standby Rate Design}

The expected standby load on a utility's system represents the level of standby demand that the utility is obligated to serve. Mathematically this can be expressed as the FOR times the maximum or contract demand of the self-generating customers. In some hours, the utility's actual standby load will be greater than the expected 
value. In other hours, it will be less than the expected value. And in many hours, it will be zero. Unlike full requirements loads, standby customers generally will not place as much of their total contracted demand on the utility during peak periods.

The reliability of self-generators affects the cost of providing backup service. The fundamental economic principle underlying the design of backup power rates is that a utility providing backup service is incurring the costs associated with the reserve capacity, which in conjunction with the self-generating capacity, assures a reliable supply of electricity to the customer. Highly reliable self-generators will require small reserve levels; less reliable self generators will require larger reserve levels.

\section{Costing and Pricing Standby Service}

One reasonable approach to costing and pricing the generation component of standby service is to quantify the amount of reserve capacity required to provide firm standby service based on an expected level of standby demand that the utility will serve over time. This can be done independently of a class cost-of-service study.

One means of establishing the generation-related costs of providing standby service is the Expected Value (EV) method, a methodology for quantifying the amount of reserve capacity required to provide standby service. The EV method is a reasonable approach for at least two reasons. First, the EV method is easy to implement. Second, this method is consistent with cost-of-service principles in that it directly measures the probability that standby customers will or will not contribute to the need for, and use of, generation capacity.

Under this method, the amount of reserve capacity required to provide standby service is equal to the product of the FOR and the standby contract capacity. The FOR used in the EV method should reflect the longrun performance of customer-owned generation facilities. The FOR used in the EV method directly reflects the probability that an outage of a self-generating customer will occur in any given hour, and therefore provides a reasonable measure of the amount of capacity that a utility must set aside to provide standby power service.

This approach results in the design of a firm standby power rate that consists of two basic components: (1) a monthly generation reservation charge, and (2) a daily, as used demand charge. These two rate components are discussed in more detail herein.

\section{Standby Generation Reservation Charge}

The standby generation reservation charge is designed as a percentage of the demand-related generation costs recovered through the regulated demand charges that are assessed to full requirement industrial (or commercial) customers in the jurisdiction under study. The appropriate percentage of the demand charge for generation for full-requirement customers to be assessed to standby customers could be developed using historical data, if available, regarding the FORs of standby customers in the utility's service area. Specifically the standby generation reservation charge would be calculated as the product of the FOR and the demandrelated generation costs underlying the applicable fullrequirements electricity rate. The standby generation reservation charge rate would be calculated and assessed on a per $\mathrm{kW}$ month basis. Recommendations in this paper would use the best performing customer generators (lowest FOR) to set rates to recognize the value of reliable systems. If an average FOR is used to develop the standby generation standby charge, the customers whose selfgenerating unit is performing the best will be paying rates above the cost to serve. Average and unreliable systems can be motivated to improve through incentives embedded in other rate elements such as the daily demand charge.

This reservation charge would be billed each month of the year as the product of the per kW-month reservation charge rate and the firm standby power demand that the utility commits to provide to the standby customer by contract (the contract demand). The reservation charge would establish a minimum monthly charge that the standby customer would pay, even if the customer did not actually take any standby power service in a given month.

Some customers may wish to contract for standby capacity that fully covers the peak output of their onsite generating units, paying for firm standby service for all of their load at a set price, whereas other customers may desire a somewhat lower level of backup. Allowing individual customers to designate a contract demand specifying the level of standby capacity they wish to purchase gives customers the option to cover only a portion of their load while paying market based pricing for any energy use above that level. 


\section{Daily, As-Used Standby Demand Charge}

On average, the monthly generation reservation charge would recover the utility's cost of providing firm standby service. When an individual standby customer requires more than the average amount of standby service in a particular billing period, it is appropriate to require the customer to pay additional charges to recognize the additional cost of providing service. For example, if an outage were to last an entire month, a standby customer cost would resemble a full-requirements customer.

A prorated, daily, as-used demand charge would apply when standby service is actually taken in a given billing period. The charge would be designed on a per $\mathrm{kW}$ day basis and assessed to the standby customer based on the maximum backup power demand that the customer imposes on the utility's system in a given day.
The standby tariff terms and conditions should make a clear distinction between the purchase of standby power and supplemental power. Without this clear distinction, a customer could be charged for backup power when the power requirement should actually be met through the customer buying supplemental power.

Finally, backup and maintenance power differ from one another and from full requirement power service in that they do not have the same coincidence with the utility's system peak. Maintenance power, by definition, would only be provided during off-peak periods or periods during the year when adequate resources are available. Consequently, it would be reasonable to discount the pro-rated daily demand charges for maintenance power service relative to the daily charges that apply for normal backup power service. 


\section{Chapter 2. Economic Analysis for Study}

$\mathrm{B}$ AI performed an economic analysis of standby tariffs for selected utilities in each of the five states included in the study. The analyses were designed to assist the state regulatory commissions in evaluating the costs and benefits associated with current standby rate designs and potential enhancements. The economic analysis compares the standby costs for specific example CHP systems to determine the impact of existing standby rates and suggested tariff changes on CHP project economics.

BAI developed a Microsoft Excel model for each of the standby tariffs addressed, quantifying the change in costs that would result from implementing the tariff modifications proposed by BAI and RAP. A description of each state-specific model is included online in Attachment 1 to this report. The spreadsheets are also publicly available for other states, customers, and stakeholders to adapt for their own circumstances. ${ }^{13}$

This chapter provides a high-level review of the process that BAI used to develop the economic modeling.

\section{Selection of Representative Customer Usage Characteristics}

The first step in developing the economic model for the selected utility tariffs was to designate the representative customer characteristics used to quantify the cost of providing standby service under the existing and alternative proposed rate designs. The customer usage and load characteristics modeled in the study were based on discussions with state regulatory commission staff. In some instances, databases of existing CHP customers in the state, or customer types most likely to develop CHP systems in the state, were used to develop the scenarios studied. However, in each instance the state regulatory staff had the final say as to the size of load that was studied. This also applied to the selection of the forced outage rates that were analyzed.

In general, the process resulted in the selection of characteristics deemed to be appropriate to represent small, medium, and large nonresidential customers.

\section{Description of Modeling Methods}

Each model calculates the costs to self-generation customers under various scenarios. Each model allows the user to input representative customer characteristics such as load factor and peak demand, as well as generating unit characteristics such as net capability and assumed outage hours. The spreadsheet includes actual standby service rates for the selected utility, including the core standby tariff and applicable riders and supplemental power tariffs.

Customer and generator characteristics and rate inputs were then used to estimate the cost of taking standby service under the applicable standby rate schedules. After developing the core spreadsheet used to model costs under existing rates, BAI in some instances developed separate spreadsheets to isolate the economic impact of implementing the proposed standby rate modifications recommended by the study for each jurisdiction. In some cases, BAI adjusted rates to simulate the proposed modifications.

\section{Discussion of Modeling Assumptions}

Each state model was designed in a manner that allows the user to select assumptions for critical inputs such as forced outage hours, unit maintenance hours, customer load size for both standby and supplemental power requirements, and customer load factor. Once these assumptions are selected, the model calculates the resulting costs under existing tariff rates. This approach gives the user the flexibility to analyze the economic impact of the existing and modified standby rates under a wide range of load and generation assumptions. Depending on the suggested tariff modifications, the model could be used to calculate the revised costs. This would require adjusting the rates in the model that calculates costs under the current tariff.

13 For state specific attachments and a link to the Excel model for each state, please go to: http://www.raponline.org/ featured-work/standby-rates-for-CHP 


\section{Identifying Potential Tariff Modifications}

BAI and RAP developed the potential tariff enhancements recommended in this study in two interrelated steps. First, BAI and RAP reviewed and analyzed the standby tariff components for each selected state utility to understand the rates, terms, and conditions of each tariff; determine how each rate component is calculated; and evaluate the manner in which the various elements of the tariff work together or potentially contradict one another. Second, BAI and RAP evaluated the tariffs against best practices in standby rate design and identified modifications to the tariffs that could enhance their efficacy for CHP applications and move them closer to a best practices model.

A detailed discussion of the proposed tariff modifications for each of the five selected utility standby rates is provided in each state-specific chapter of this report. 


\section{Chapter 3. Arkansas \\ Standby Rates for Customers of Entergy Arkansas, Inc.}

\section{Description of Standby Rates}

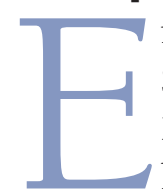

ntergy Arkansas, Inc. (EAI) offers a Standby

Service Rider (SSR) under Rate Schedule No.

20. The SSR is available to customers who

have their own generating equipment and have executed a contract for standby service with EAI. The SSR is comprised of four service offerings:

1. Reserved Service is the electric energy and capacity that EAI stands ready to supply during a scheduled or unscheduled outage of the customer's on-site generation equipment.

2. Maintenance Service is the electric energy and capacity supplied by EAI during scheduled outages of the customer's generating equipment. Maintenance Service is available during the service months of October through May and during the off-peak hours of the service months June through September.

3. Non-Reserved Service is the electric energy and capacity EAI may supply during a scheduled outage of the customer's on-site generation equipment. Non-Reserved Service is only available during the service months of October through May. EAI, in its sole discretion, may approve or deny any request for Non-Reserved Service.

4. Backup Service is the electric energy and capacity supplied by EAI during an unscheduled outage of the customer's electric generating equipment, as well as the energy and capacity supplied by EAI during a scheduled outage that exceeds the sum of scheduled Maintenance Service and any scheduled Non-Reserved Service.

\section{Description of Standby Charges}

The SSR tariff includes eight charges:

1. A monthly customer charge

2. A monthly reservation charge

3. Seasonal maintenance demand charges expressed on a daily basis

4. Seasonal backup demand charges also expressed on a daily basis

5. A monthly demand charge for Non-Reserved Service
6. Seasonal maintenance energy charges

7. Seasonal backup energy charges

8. Seasonal energy charges for Non-Reserved Service

The reservation demand charge is a flat $\$ / \mathrm{kW}-$ month rate across the entire year. EAI's demand and energy charges for Maintenance and Backup Service vary by season. The seasonal charges are higher during the billing months of June through September (the "Summer Period"), while charges are lower for all other months of the year (defined as the "Other Period"). The tariff defines on-peak hours for the Summer Period and the Other Period. However, SSR rates (except for seasonal maintenance energy charges, as noted above) do not contain any time-of-use differentiation between on-peak and off-peak periods.

SSR demand charges, including the reservation charge, are bundled charges that incorporate generation, transmission, and distribution costs. The reservation charge and the various demand and energy charges vary with the customer's voltage level of service (secondary, primary, or transmission). In addition, these charges are adjusted to reflect the customer's metering points. The energy charges in the SSR are consistent with the energy charges in EAI's full service rates - Large General Service (LGS) and Large Power Service (LPS).

\section{Assessment of Standby Rates}

The following are suggested modifications to EAI's standby tariffs for consideration:

- Lack of transparency and clarity. None of the EAI rate schedules we reviewed unbundle generation, transmission, and distribution charges, so customers do not know how much they are paying for each component of service and what charges might be avoidable with reliable onsite generation. Furthermore, some provisions of the SSR tariff appear to be in conflict with one another. For example, the tariff indicates that during the months of June through September maintenance energy can only be scheduled during off-peak 
periods. However, the same provision also states that maintenance service will not be scheduled for a continuous period of less than one day. The latter requirement dictates that maintenance energy must effectively be scheduled during on-peak hours.

- Lack of price signals to provide incentives to improve operation of on-site generating units and use utility resources more efficiently. Adding daily demand and energy charges for both backup service and maintenance service could achieve these goals. Daily demand charges could be unbundled into separate charges for the generation, transmission, and distribution cost components. In addition, the generation and transmission components of the demand charge, as well as the charge for non dedicated distribution facilities, could be assessed only during the on-peak period. Furthermore, seasonal energy (per kWh) charges could distinguish on-peak and off-peak usage to better capture the costs that EAI is actually incurring to serve customer-generators.

\section{- Inadequate interruptible standby service} option. Although the standby tariff allows the customer to purchase Non-Reserved Service, which functions in a similar manner to interruptible service, EAI retains the discretion to deny a customer's request for this service. This means that the SSR tariff does not guarantee a customer's ability to purchase interruptible standby service. Also, it appears that if a customer purchases Non-Reserved Service for a scheduled outage, the customer pays the demand charges on the supplemental rate as opposed to the daily maintenance service demand charges contained in the SSR.

- Inadequate flexibility. EAI's standby tariff does not provide the standby customer with adequate flexibility to meet its standby requirements through alternative means such as self-dispatch, competitive market purchases, or special contracts.

Possible remedies for these issues are set forth below.

\section{Potential Modifications to Standby Tariff}

Following are suggested modifications to EAI's SSR tariff:

\section{The SSR reservation demand charge should} be unbundled into generation, transmission, and distribution components. The SSR tariff bundles these cost components into one reservation demand charge, making it difficult to assess the level of generation, transmission, and distribution costs that a standby customer is paying through the reservation charge. Unbundling these cost components would make the reservation charge more transparent. In addition, unbundling these costs would allow EAI to better reflect load diversity in the design of the demand charges for shared distribution and transmission facilities, as further discussed in recommendation number 9 .

2. The unbundled generation component of the reservation demand charge for standby service should be set such that it is equivalent to the best FOR exhibited by any generating unit on EAI's system. This standby generation charge can be calculated by multiplying this best FOR by the demand charge in the customer's otherwise applicable full-requirements tariff.

3. The reservation demand charge should be differentiated by season. Currently the reservation demand charge is a flat $\$ / \mathrm{kW}$-month for the entire year. However, all of the demand charges on supplemental rate schedules LGS and LPS are seasonal. The energy charges in the SSR are also seasonal. Thus, introducing seasonality into the design of the reservation demand charge would ensure consistency with the design of other rate components in EAI's tariff. This rate design modification would also more accurately reflect the seasonal variations in EAI's cost of service.

4. The daily maintenance and backup demand charges should apply only during on-peak periods. The SSR tariff defines on-peak hours for the Summer Period as 1 p.m. to 8 p.m. Monday through Friday. For the Other Period, on-peak hours are 7 a.m. to 6 p.m. Monday through Friday. The SSR tariff should be modified to specify that backup and maintenance demand charges would apply only during these on-peak hours. This would send an appropriate price signal to customers that would discourage them from imposing demands on EAI's system during times when EAI's generation reserve margins are at their tightest levels. Also, from a maintenance standpoint, customers can more effectively schedule their unit maintenance outages when demand charges are only imposed during the on-peak periods. (Of course, customers must notify EAI of any maintenance outage in advance.) Furthermore, demand charges that reflect time of use would be consistent with the requirement that maintenance service in the Summer Period be taken only during off-peak hours. 
5. The daily backup and maintenance energy charges should be further differentiated on a time-of-use basis. In addition to the existing seasonal variation in these energy charges, the standby tariff should separate backup and maintenance energy charges for on-peak and offpeak hours. This modification would ensure that backup and maintenance energy charges more closely track EAI's incremental cost to provide energy to standby customers.

6. Customer-generators should have the option to buy backup power from the market through the utility and thereby avoid the monthly reservation charge for standby generation service. Under this approach, the standby customer would purchase backup energy from the utility only on an as-needed basis. Such purchases would be priced at the real time locational market price applicable to the geographic location at which the customer takes service. In addition, the customer would pay a share of any contracted capacity purchased, an allocated portion of transmission costs and ancillary services, and a small administrative fee to cover the utility's procurement cost.

7. Customer-generators should have the option to provide the utility with a load reduction plan that demonstrates their ability to reduce a specified amount of load within a required timeframe to mitigate all or a portion of backup demand charges. This approach would establish the standby customer's generation reservation demand charge as a function of the load that the utility would be required to meet through standby service. This standby service amount would be less than the rated output of the customer's self-generating unit because it would incorporate an adjustment for the amount of load reduction that the customer can achieve. This option would give the standby customer the flexibility to use demand response to meet all or a portion of its standby needs. The utility would retain the discretion to approve each standby customer's load reduction plan, including whether the customer can shed load with a sufficient response time that would allow the utility to avoid generation reserve costs in accordance with the utility's applicable reliability criteria.

8. The Non-Reserved Service feature of the SSR tariff should be modified to facilitate the provision of interruptible standby service. EAI essentially offers a full interruptible option through the Non Reserved Service provisions of the SSR. However, this service does not guarantee the provision of standby energy to support a maintenance outage. Even if such an outage is scheduled, the customer is required to pay significantly higher demand charges than would be incurred for a traditional maintenance outage under the tariff. The Non-Reserved Service provisions should be modified to include reasonable charges for maintenance outages and a requirement that such outages be scheduled at a mutually agreeable time for EAI and the customer.

\section{Standby charges for shared transmission} and distribution facilities should reflect the load diversity of CHP customers. The rates for shared transmission and distribution facilities, such as substations and primary feeders, should reflect load diversity. Load diversity recognizes that, except for facilities dedicated to a specific customer, the transmission and distribution system is not specifically designed to meet a single customer's needs, but is instead designed to serve the coincident peak demand by a pool of customers. Load diversity can be recognized by designing transmission and distribution demand charges on a coincident peak demand basis or by assessing charges for shared transmission and distribution facilities based on the demand established by the standby customer only during on-peak hours.

10. Standby rate design should avoid demand ratchets. Demand ratchets should not apply to EAI's charges to standby customers for shared distribution facilities. Instead, customer-generators should pay for non-dedicated distribution facilities only when they are actually purchasing backup or maintenance power in a particular month.

11. Standby tariffs should be concise and easily understandable. Customers who may consider installing a cogeneration system will have a difficult time understanding all of the charges that they may pay under various circumstances with the standby tariff and riders that EAI has in place today. For example, the maintenance service provision of the SSR tariff requires that maintenance outages during the summer season be performed only during the off-peak period. However, the tariff also states that maintenance service during the summer months will not be scheduled for a continuous period of less than one day. The latter provision essentially requires the customer to perform maintenance 
during the on-peak hours of the summer months, creating an internal conflict in the maintenance service provisions of the tariff.

\section{Standby tariffs should specify the} circumstances under which special contracts may be warranted. Customers who have specific needs or operating conditions may require special contracts for standby power. EAI's standby tariffs should therefore contain provisions that would allow standby customers who demonstrate unique requirements to negotiate customer-specific standby service contracts with the utility. These customer specific contracts would be submitted to the Arkansas Public Service Commission for review and approval, subject to appropriate confidentiality restrictions that may be required to protect the customer's commercially sensitive information.

\section{Economic Analysis of Standby Tariff}

An economic analysis was performed to estimate the monthly costs incurred by EAI customers who have onsite generation under the SSR tariff. To calculate these costs, an economic model was developed that estimates the monthly costs for reservation, maintenance service, backup service, and supplemental power. See Attachment Arkansas 1 online for a detailed description of the model.

The economic analysis calculated costs for three customer load sizes with the following customer generation parameters:

\section{Small Load}

a. Total Demand: 1,500 kW at 70-percent load factor

b. Customer Generation Demand: $700 \mathrm{~kW}$ at 100-percent load factor

c. Forced Outage Hours: 146

d. Maintenance Hours: 73

e. Supplemental Service on Rate Schedule LGS at Primary Voltage

\section{Medium Load}

a. Total Demand: 6,000 kW at 80-percent load factor

b. Customer Generation Demand: 4,000 kW at 100-percent load factor

c. Forced Outage Hours: 73

d. Maintenance Hours: 73

e. Supplemental Service on Schedule LGS at primary voltage

\section{Large Load}

a. Total Demand: 30,000 kW at 75-percent load factor

b. Customer Generation Demand: 20,000 kW at 100-percent load factor c. Forced Outage (Backup Service) Hours: 37

d. Maintenance Hours: 37

e. Supplemental Service on Rate Schedule LPS at transmission voltage

Attachment Arkansas-2 summarizes SSR costs at the existing tariff rates for each representative customer using the BAI economic model. Note that a transmission-level customer could take service under Schedule LGS or Schedule LPS. BAI opted to model the transmissionlevel customer's costs assuming that service is taken under Schedule LPS, in order to ensure that both of EAI's supplemental service tariffs would be modeled in the study.

In addition, an economic analysis was performed to estimate the bill impacts of the suggested tariff improvements. The modeled tariff charges used to develop these bill impacts are not based on a formal original cost of service study. Rather, the authors relied on the charges in the current utility rate schedules, with adjustments based on the judgment of the study authors using the criteria appearing in the recommendations and Chapter 1. Following are the principal features of the modeled tariff charges:

1. A generation reservation charge was developed to reflect the performance of the best generating unit. For purposes of this analysis, the reservation charge was assumed to be five percent of the applicable generation and transmission demand charges, as the current SSR tariff charges are not unbundled.

2. A daily backup demand charge for power purchased during a forced outage was developed. If the selfgenerating unit was out of service for a full month, the charges would be equivalent to the applicable full requirements tariff.

3. The daily maintenance demand charges were set at 50 percent of the backup charges. The maintenance costs represent a discount from the daily backup demand charges because maintenance outages must be pre-scheduled with the utility during time periods when the utility's marginal cost of service is low. The current SSR maintenance daily demand charges are approximately 44 percent of the current daily backup demand charges. Therefore, this assumption is consistent with the SSR tariff.

4. The distribution rates were adjusted to reflect load diversity. The distribution component of the reservation charge was adjusted to include only an estimate of costs associated with dedicated distribution facilities. The non-dedicated 
distribution costs were recovered through the daily demand charges described earlier. Because the current charges are bundled and no distinct distribution charges are available, the distribution component of the reservation charge was estimated by the study authors.

Attachment Arkansas 3 compares the charges/rates and costs that would be incurred under the existing standby tariff charges relative to the modified charges. The calculations in this attachment exclude all energyrelated costs associated with purchases of fuel and supplemental power. With the exception of the VAR, the calculations also exclude costs associated with utility riders because they represent a small portion of the total cost of providing service to the customer, and none of the standby tariff modifications proposed in this study affect the excluded riders. The VAR was used to develop separate primary and transmission charges.

As Attachment Arkansas-3 shows, adjustments made to the reservation charges in the SSR tariff and the various supplemental rates to reflect the performance of the best self-generating unit on the utility system and load diversity result in reduced charges for the three load scenarios studied. The revised reservation charges are estimates; they were not developed from any cost of service study. Because rates are not unbundled, the authors used their judgment to estimate a breakdown of the generation, transmission, and distribution components of the reservation charges.

Adjustments also were made to reflect the recommendation to apply backup and maintenance charges only to demands that occur during on-peak weekday hours. As a result, the cost of providing standby service must be recovered over an approximate 20day period as opposed to a 30 day period, increasing the per-unit charge relative to the current SSR tariff. Backup and maintenance charges were further adjusted to recognize load diversity and to capture transmission and distribution costs that are not recovered through the modified reservation charge.

An analysis was performed showing customer savings for the Summer Period resulting from taking both backup and maintenance service only during the off-peak period. These savings result from applying backup and maintenance demand charges only during on-peak hours.

Customers who impose demands for backup or maintenance service during on-peak periods will incur higher costs under our simulation of modified SSR charges. This is because the backup and maintenance charges must be increased relative to the current tariff charges to reflect the fact that cost recovery will occur only during the on-peak period.

Our analysis does not reflect savings and costs associated with implementing our recommended timeof-day energy prices. The results would have been similar to the results discussed earlier for time of day demand charges. That is, energy usage during the off-peak periods would produce savings, while on-peak energy usage would increase costs.

It is important to note that customers taking standby service on an interruptible basis would avoid both the utility's standby reservation charges and backup charges associated with any unscheduled outages. (The customer would still be required to pay for any dedicated distribution facilities.) However, the customer would default to the full-requirements tariff, and pay the generation, transmission, and distribution charges in that tariff, if the customer is unable to interrupt its load in compliance with the standby tariff conditions. For example, a transmission customer would pay all of the charges in EAI's LPS tariff. 


\section{Chapter 4. Colorado Standby Rates for Customers of Public Service Company of Colorado}

\section{Description of Standby Rates}

$\mathrm{P}$

ublic Service of Colorado (PSCo) provides

Transmission Standby Service under Schedule

TST and Primary Standby Service under

Schedule PST. The tariffs are for commercial and

industrial customers who operate generating equipment

in parallel with the utility's electric system and require 10 $\mathrm{kW}$ or more of standby capacity service.

Standby service charges include monthly reservation fees, including a Service and Facility Charge, an Interconnection Charge, a Generation and Transmission Standby Capacity Reservation Fee, and a Distribution Standby Capacity Fee. In addition, the standby tariffs include a usage charge for demand and energy. The demand charge is only applicable after the customer has used the allowed Grace Energy Hours for standby service, set at 1,051 hours.

The customer's standby contract capacity is set forth in a standby service agreement. The quantity of standby capacity can be set at different levels for the summer and winter seasons.

For customers who have a standby contract capacity ranging from 10 to $10,000 \mathrm{~kW}$, maintenance on the generating unit must occur during the calendar months of April, May, October, or November. Customers must provide PSCo with written notice of scheduled maintenance prior to the beginning of the maintenance period.

Customers who have a standby contract capacity greater than 10,000 kW must provide to the utility an annual projection of scheduled maintenance. PSCo must authorize the schedule in advance. The amount of advance notice that the customer must provide depends on the expected duration of the maintenance outage. For example, if a customer requests an outage longer than 30 days, the required notice is 90 days. Maintenance outages cannot exceed six weeks in any 12 -month period. Qualified scheduled maintenance time does not count against the customer's Grace Energy Hours.

\section{Description of Rate Components}

Schedules TST and PST contain the following rate components:

1. A monthly Reservation Fee consisting of a Service Charge and a Facilities Charge;

2. An Interconnection Charge (only applicable to Schedule TST);

3. A Generation and Transmission Standby Capacity Reservation Fee; and

4. A Distribution Standby Capacity Fee (only applicable to Schedule PST).

For Schedule TST, the Service and Facilities Charge and Interconnection Charge are customer specific. In the case of Schedule PST, the Service and Facilities Charge is fixed for all customers at $\$ 305$ per month, and no Interconnection Charge applies.

The Generation and Transmission Standby Capacity Fee covers capacity costs up to the allowed Grace Energy Hours for standby service (1,051 hours), assuming a 100-percent capacity factor for the customer's generating unit, for an annual period that begins October 1. The annual Grace Energy consumed by the customer under the tariff is equal to the customer's standby service hours multiplied by the customer's standby contract capacity. If the customer exceeds the annual allowed Grace Energy Hours, the customer is billed for any used capacity related to a forced outage of its generating unit at a demand charge that is approximately equivalent to the demand charge the customer would pay on the applicable supplemental (full-requirements) tariff. The standby tariffs also include an energy usage charge.

\section{Assessment of PSCo's Standby Rates}

PSCo's standby tariffs lack adequate price signals that could provide incentives to standby customers to improve the operation of their generating units or to make more efficient use of local utility resources. For example, the tariffs do not incorporate daily generation demand charges that would give standby customers an incentive to reduce the duration of their generating unit outages. 
The generation reservation charges also lack time-of-use price signals that would encourage customers to shift their use of the utility's resources to off-peak periods.

In addition, the design of PSCo's standby charges fails to recognize load diversity, resulting in rates that send inaccurate price signals to customers regarding the cost drivers behind the utility's investments. Furthermore, PSCo's standby rates lack price transparency because the generation and transmission costs are bundled together in the Reservation Fee component of the tariff.

Finally, PSCo's tariffs do not provide the standby customer with adequate flexibility to meet its standby requirements through alternative means such as selfdispatch and the purchase of market-priced power.

Possible remedies for these issues are set forth below.

\section{Potential Modifications to PSCo's Standby Tariffs}

Following are suggested modifications to PSCo's standby tariffs for consideration:

1. The monthly standby charge (Reservation Fee for Generation and Transmission Capacity) should be set such that it is equivalent to the best FOR exhibited by any generating unit on PSCo's system. This standby generation charge can be calculated by multiplying this best FOR by the demand charge in the customer's otherwise applicable full requirements tariff. For example, the Summer period demand charge in Schedule TG for a transmission voltage level customer is $\$ 9.68$ per kW. Multiplying this charge by a FOR of five percent produces a Generation and Transmission Reservation Fee of $\$ 0.484$ per $\mathrm{kW}$ for the summer months.

2. Daily standby generation demand charges should be assessed to provide incentives to improve the performance of self-generating units. In addition to the Generation and Transmission Capacity Reservation Fee, standby customers should pay daily demand charges when they actually take backup power from the utility. To calculate a daily demand charge, divide the demand charge specified in the appropriate full-requirements tariff, adjusted to exclude the standby portion, by the average number of billing days in a month. Under this rate structure, the customer would pay the same amount as the supplemental rate if the customer took backup service for the entire month. The standby customer also would pay the utility's applicable fuel charges as well as all other applicable riders.
3. Customer-generators should have the option to buy backup power from the utility at market prices and thereby avoid monthly reservation charges for standby service. Under this approach, the standby customer would purchase backup energy from the utility on an as needed basis at wholesale market prices. In addition to these energy costs, the customer would pay a share of any capacity costs, an allocated portion of transmission costs and ancillary services, and a small administrative fee to cover the utility's costs for procurement.

4. Customer-generators should have the option to provide the utility with a load reduction plan that demonstrates their ability to reduce a specified amount of load $(\mathrm{kW})$ within a required timeframe to mitigate all or a portion of backup demand charges. This approach would establish the standby customer's Reservation Fee as a function of the load that the utility would be required to meet through standby service. This standby service amount would be less than the rated output of the customer's generating unit because it would incorporate an adjustment for the amount of load reduction that the customer can achieve. This option would give the standby customer the flexibility to use demand response to meet all or a portion of its needs. The utility would retain the discretion to approve each customer's load reduction plan, including whether the customer can shed load with a sufficient response time to allow the utility to avoid generation reserve costs in accordance with applicable reliability criteria.

5. The generation and transmission cost components of the Reservation Fee should be unbundled. Under PSCo's current standby rate structure, it is difficult to assess the level of generation charges and transmission charges that a standby customer is paying in the Reservation Fee. This problem exists in both the standby tariffs and the supplemental tariff. Unbundling the generation and transmission cost components would make the rate design of the Reservation Fee more transparent.

6. Standby charges for shared distribution facilities should reflect load diversity. Customers should pay for the cost of distribution facilities that are dedicated entirely to serve an individual customer through the Reservation Fee. However, charges for shared distribution facilities such as substations and primary feeders should 
reflect load diversity. Load diversity recognizes that a given portion of the distribution system is not specifically designed to meet a single customer's needs, but is instead designed to serve the coincident peak demand for distribution services that is established by a pool of customers. Load diversity can be recognized by designing the distribution demand charges on a coincident peak demand basis.

7. Standby backup demand charges for generation and distribution service should apply only during on-peak hours. This rate design would provide standby customers with an incentive to shift their use of the utility's assets to off-peak hours, when the cost of providing service is typically much lower. If PSCo's capacity costs are driven by customer demands established during defined on-peak periods, those same time periods should be used to establish the timeframe during which standby demand charges would be applicable.

\section{Economic Analysis of Standby Tariffs}

An economic analysis was performed to estimate the monthly costs incurred by PSCo customers who have on-site generation under Schedules PST and TST. To calculate these costs, an economic model was developed that estimates the monthly costs for reservation and supplemental power. Attachment Colorado 1, available online, describes the model in detail.

The economic analysis calculated costs for three load sizes and the following customer generation parameters:

\section{Small Load}

a. Total Demand: 1,500 kW at 70-percent load factor

b. Customer Generation Demand: $700 \mathrm{~kW}$ at 100-percent load factor

c. Outage Hours: 40

d. Supplemental Service on Schedule PG at primary voltage

\section{Medium Load}

a. Total Demand: 6,000 kW at 80-percent load factor

b. Customer Generation Demand: 4,000 kW at 100-percent load factor

c. Outage Hours: 50

d. Supplemental Service on Schedule PG at primary voltage

\section{Large Load}

a. Total Demand: 30,000 kW at 75-percent load factor

b. Customer Generation Demand: 20,000 kW at 100-percent load factor c. Outage Hours: 40

d. Supplemental Service on Schedule TG at transmission voltage

Attachment Colorado-2 summarizes Schedule PST and TST costs at the existing tariff rates for each scenario using the BAI economic model.

In addition, BAI performed an economic analysis to estimate the bill impacts of the suggested tariff improvements. It should be noted that the modeled tariff charges used to develop these bill impacts are not based on a formal original cost of service study. Rather, the rate assumptions used in the economic model were developed by relying on the charges found in the current utility rate schedules, with appropriate adjustments based on the judgment of the study authors. The principal features of the modeled tariff charges include the following:

1. A generation reservation charge was developed to reflect the performance of the best generating unit. For purposes of this analysis, the reservation charge was assumed to be five percent of the applicable generation and transmission demand charges.

2. A daily backup demand charge for power purchased during a forced outage was developed. If the selfgenerating unit was out of service for a full month, the cost would be equivalent to the cost incurred on the otherwise applicable full requirements tariff.

3. The distribution rates were adjusted to reflect load diversity. The distribution component of the reservation charge was adjusted to include only an estimate of costs associated with dedicated distribution facilities. The non-dedicated distribution costs were recovered through the daily demand charges described earlier. Because the current charges are bundled and no distinct distribution charges are available, the distribution component of the reservation charge was estimated by the study authors.

Attachment Colorado 3 compares the charges/rates and costs that would be incurred under the existing standby tariff charges relative to the modified charges. The calculations exclude all costs associated with purchases of supplemental power. The calculations also exclude costs associated with all utility riders because none of the standby tariff modifications proposed in this study affect charges in the riders.

The adjustments to reservation charges to reflect the performance of the best self-generating unit on the utility's system and to reflect load diversity result in reduced reservation charges for the load scenarios 
studied. The revised reservation charges are estimates; they were not developed from a cost-of-service study. Daily demand charges were created and modeled for each day where the model simulates a forced outage. Consistent with the current tariff, scheduled maintenance outages do not trigger demand charges.

In addition, the Grace Energy Hours provision was eliminated. The customer would simply incur daily demand charges for each day associated with an unscheduled outage.

The study authors did not have the data required to develop on-peak demand charges. Assuming that the utility's capacity needs and costs are driven by defined on-peak periods, demand charges should be applied only during on-peak periods.

Page 3 of Attachment Colorado-3 graphically compares the cost associated with PSCo's current standby tariffs and the costs associated with the suggested revisions. The Primary Service scenario is applicable for Schedule PST and the Transmission Service scenario is applicable for Schedule TST. The attachment includes the assumptions used to develop the graphs.

Customers taking standby service on an interruptible basis would avoid both the standby reservation charges and backup charges associated with any unscheduled outages. (The customer would still be required to pay for any dedicated distribution facilities.) However, the customer would default to the full-requirements tariff, and pay the generation, transmission, and distribution charges in that tariff, if the customer is unable to interrupt its load in compliance with the standby tariff conditions. 


\section{Chapter 5. New Jersey Standby Rates for Customers of Jersey Central Power \& Light}

\section{Description of Standby Rates}

- ersey Central Power \& Light offers a Standby Service Rider (STB) that is available to customers who have their own generating equipment. Rider STB is not available in any month in which the availability of the customer's generating unit does not exceed 50 percent. Rider STB is an abbreviated, but complex, standby tariff. The rider consists of a single Standby Demand Charge to recover the cost of distribution service provided by Jersey Central. The formula for the charge contains two equations, and the customer's monthly bill is based on whichever equation produces the greatest charge.

The first equation of the Standby Demand Charge is the sum of two charges:

Part A: The Demand Rate (DR) per kW of the applicable service classification times the Billing Demand (BD) plus

Part B: The Standby Rate (SR) per kW times the lesser of either the Maximum Monthly (MM) on-peak load of the facility or the annual Average Generation (AG) during the on-peak time periods

Part A of the equation reflects the cost of distribution service for supplemental power. BD is determined by subtracting AG on-peak from the customer's MM on-peak load of the facility. However, BD is never allowed to be less than zero. Consequently, if the customer's generation provides less than the facility's total load requirement (i.e., AG < MM), the BD represents the supplemental load necessary to serve the facility, priced at the applicable supplemental service demand charge. However, if the customer's generation is greater than what the facility requires (i.e., $\mathrm{AG}>\mathrm{MM}$ ), the $\mathrm{BD}$ is zero. In the latter situation, no supplemental service demand charge is assessed because the customer's own generation can supply 100 percent of the customer's load requirements.

Part B of the equation reflects the cost of distribution service for standby service and is based on the lesser of MM on-peak load or AG. Thus, if the customer's own generation is less than the facility's total load requirement, the standby rate is assessed on the basis of AG. On the other hand, if the customer's generation capacity exceeds the facility's load requirements, the standby rate is assessed only on the customer's total on-peak load (MM).

The sum of the Part A and Part B charges is then compared to the results of the second equation of the Standby Demand Charge formula. The second equation is simply the Rider STB standby rate per $\mathrm{kW}$ times the Contract Demand (CD). The CD is the lesser of (1) the Capacity Rating of the generation facility, or (2) the greater of the MM facility on-peak load or the highest MM facility on-peak load during the most recent 12 months. For example, if the customer's own generation capacity is less than its MM facility on-peak load, this second equation will assess the standby charge based on the capacity rating of the generator. Alternatively, if the customer's generation is greater than what the facility requires, the standby rate is assessed based on the highest on-peak load of the facility over the most recent 12-month period.

A critical component of Rider STB is the determination of AG during on-peak times. Each month, AG is calculated and the most recent 12 months of AG are averaged for use in the monthly bill. To calculate the monthly AG, the customer's energy production during on-peak hours is divided by 260 hours (the full number of on-peak hours in each month) less any scheduled maintenance hours. However, the tariff provides that the scheduling of maintenance hours is permitted only for customers receiving service under Rider STB as of February 25, 1993.

The other caveat of Rider STB is that a customer's generating unit must have a FOR of less than 50 percent in order for the Rider to be available to the customer. If the customer's generation has an unscheduled outage that reduces its on-peak availability below 50 percent for the month, the customer's load for the month is served 
under the otherwise applicable full-requirements service classification.

\section{Assessment of Standby Rates}

A general concern with Jersey Central's standby rates is that the rate design may be too complex. Simplicity and ease of understanding are commonly recognized as appropriate rate design goals.

Also, the generator availability factor limitation is restrictive. Similarly, the standby tariff appears to impose undue constraints on the ability of customers to schedule maintenance outages of their generating units. Easing these restrictions would make it easier for customers to install and operate on-site generation.

Possible remedies for these issues are set forth below.

\section{Potential Modifications to Standby Tariff}

Following are suggested modifications to Jersey Central's standby tariffs for consideration:

\section{Scheduled maintenance hours should be} allowed for all standby customers. Under the current Rider STB, it appears that customers who commenced service under the rider after February 25, 1993 are not allowed to schedule maintenance for their generating units. The ability to schedule maintenance outages is critical for on-site generation.

2. Standby service should be available to all self-generating customers regardless of the availability factor of their generating units. Under the terms of Rider STB, any customer whose generation availability does not exceed 50 percent would default to the full requirements service tariff. The distribution demand charges in the full requirements tariffs are higher than the distribution charges in Rider STB. A more reasonable approach would be to structure Rider STB in a manner that gradually increases the cost of standby service as a standby customer's generation availability declines below 50 percent. Under this approach, the Rider STB demand charge would equal the fullrequirements service demand charge only when the availability factor of the customer's generation unit fell to zero.

3. Standby tariffs should be concise and easily understandable. Customers who may consider installing on-site generation systems could have a difficult time understanding the different types of demand measurements that could affect the level of charges that they would pay under the STB Rider. The tariff could be simplified by imposing a set standby demand charge that assumes 100-percent availability of a customer's self-generating unit, accompanied by a daily demand charge that would recover the cost of backup distribution capacity purchased by the standby customer during forced outages and scheduled maintenance.

4. Standby charges for shared distribution facilities should reflect load diversity. The existing Rider STB voltage-level charges are likely below cost of service. The Rider STB voltage level charges are substantially less than the voltage level charges in the full requirements service tariffs. The difference in these rates indicates that the distribution charges for Rider STB were developed to encourage self-generation.

\section{Economic Analysis of Standby Tariffs}

An economic analysis was performed to estimate the monthly costs incurred by Jersey Central customers who have on-site generation under Rider STB. To calculate these costs, BAI developed an economic model that estimates the monthly costs for distribution energy charges, riders, and standby charges for Rider STB and the applicable service classifications (supplemental service). Attachment New Jersey 1, available online, describes the model in detail.

The model calculated costs for three load sizes and the following customer generation parameters:

\section{Small Load}

a. Total Demand: 1,500 kW at 70-percent load factor

b. Customer Generation Demand: $700 \mathrm{~kW}$ at 90-percent generator availability

c. Maintenance Hours: 50

d. Supplemental Service on Rate Schedule GP at primary voltage

\section{Medium Load}

a. Total Demand: 6,000 kW at 80-percent load factor

b. Customer Generation Demand: 4,000 kW at 85-percent generator availability

c. Maintenance Hours: 60

d. Supplemental Service on Schedule GT at high transmission voltage 


\section{Large Load}

a. Total Demand: 30,000 kW at 75-percent load factor

b. Customer Generation Demand: 20,000 kW at 90-percent generator availability

c. Maintenance Hours: 30

d. Supplemental Service on Rate Schedule GT at transmission voltage

Attachment New Jersey-2 summarizes Rider STB costs at the existing tariff rates for each representative customer using BAI's economic model. The economic model did not include costs for generation service. Generation service for these customers is typically supplied by a third-party supplier, and including any cost estimate was deemed to be not necessary and speculative by the authors.
In addition, an economic analysis was performed to estimate the bill impacts of the suggested tariff improvements described earlier. Modeled tariff charges used to develop these bill impacts are not based on a formal cost of service study. Rather, the rate assumptions used in the economic model were developed by relying on the charges in the current utility rate schedules, with adjustments based on the judgment of the study authors. The principal feature of the modeled tariff charge is making Rider STB available to all self-generating customers regardless of the availability of the generating unit in any month.

Attachment New Jersey 3 compares costs that would be incurred under the existing standby tariff charges compared to the modified charges. The calculations exclude costs associated with all other utility riders. None of the standby tariff modifications proposed in this study affects the excluded riders. 


\section{Chapter 6. Ohio Standby Rates for Customers of AEP Ohio}

\section{Description of Standby Rates}

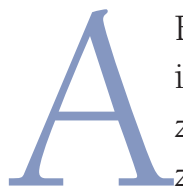

EP Ohio operates as Ohio Power Company in the state of Ohio. The utility has two rate zones: the Columbus Southern Power rate zone and the Ohio Power rate zone. Each of these rate zones has a standby tariff, Schedule SBS (Standby Service), applicable to customers who purchase power from Ohio Power Company. In addition, each rate zone has an open access standby tariff, Schedule OADSBS (Open Access Distribution Standby Service), which applies to customers who purchase power from a thirdparty supplier.

The standby tariff schedules and associated riders in each of the rate zones are identical except for the level of the charges. In addition, the terms and conditions for the provision of distribution service are the same for both Schedule SBS and Schedule OAD SBS. As a result, it is only necessary to address the terms and conditions of the tariffs for a single rate zone.

It is anticipated that by the end of 2015 all AEP Ohio Power Company customers will be able to choose a Certified Retail Electric Service (CRES) provider. Schedule OAD-SBS will apply to distribution-only customers who take service from a CRES provider. Schedule SBS will apply to distribution and Standard Service Offer (SSO) customers - those who do not take service from a CRES provider. SSO customers will pay energy prices based on the results of a competitive bidding process (an energyonly auction).

\section{SCHEDUle SBS - STANDBY POWER SUPPLIED BY OHIO POWER COMPANY}

Schedule SBS is available to customers who have an on-site source of electric energy supply and a standby generation supply requirement of $50,000 \mathrm{~kW}$ or less. The standby contract capacity in $\mathrm{kW}$ is initially established by mutual agreement between the customer and the utility.

The standby customer pays a demand charge for generation that is a function of the FOR and the supply voltage. The utility offers a choice of six specified FORs $(5,10,15,20,25$, and 30 percent), with higher outage rates corresponding to higher generation demand charges. The customer can purchase backup power for a designated number of hours per year. The number of hours for which backup power is purchased varies as a function of the outage rate that the customer selects. If the customer requires backup power in excess of the designated hours during the control year, the customer defaults to the applicable full service tariff for the rest of the contract period.

For example, a primary voltage customer in the Columbus Southern Power Rate Zone who estimates a FOR of 15 percent will pay a monthly generation charge of $\$ 2.455 / \mathrm{kW}^{14}$ regardless of whether the customer actually buys backup power. The monthly generation charge allows the customer to buy back up energy for up to 1,314 hours ( 15 percent of 8,760 hours) during the year. When the customer exceeds the allowed outage hours, the customer is billed under the appropriate supplemental rate schedule. In that instance the monthly generation demand charge increases significantly and can become $\$ 9.662 / \mathrm{kW}^{15}$ (Schedule GS-3, Primary Voltage).

In addition to the generation charges discussed earlier, the customer pays a monthly distribution standby charge that is a function of the customer's voltage level of service. The distribution charge is assessed on a $\$ / \mathrm{kW}$ basis and recovers secondary and primary voltage level distribution costs. The distribution charges are not a function of the FOR and are the same for each FOR by voltage level (secondary and primary).

14 Tariff rate in place at the time of BAI's economic analysis. In September 2012, the charge increased to $\$ 2.671 / \mathrm{kW}$.

15 The charge increased to $\$ 10.511 / \mathrm{kW}$ in September 2012. 
Subtransmission and transmission costs that are incurred to serve standby customers are recovered through a Transmission Cost Recovery Rider. This rider allows the customer to purchase subtransmission/ transmission service for a set number of hours based on the selected FOR. The rider rate design is structured in the same manner as the generation demand charges described previously.

In the Columbus Southern Power Rate Zone, generation and transmission charges are the same for sub transmission and transmission customers. In the Ohio Power Rate Zone, there are separate generation charges for sub transmission and transmission customers, but the transmission rider charges are the same for both voltage levels.

\section{SCHEDULE OAD-SBS - POWER SUPPLIED BY A THIRD PARTY}

Schedule OAD-SBS is available to customers who have an on-site source of electric energy supply and a standby distribution requirement of $50,000 \mathrm{~kW}$ or less. The standby contract capacity in $\mathrm{kW}$ is initially established by mutual agreement between the customer and the utility.

Under this tariff schedule, the customer pays the monthly distribution standby charge that is applicable to Schedule SBS customers (described previously). Schedule OAD-SBS customers taking transmission service do so under the terms and conditions of the applicable open access transmission tariff (OATT), as filed with and accepted by the Federal Energy Regulatory Commission (FERC).

\section{Assessment of Standby Rates}

A central concern with AEP Ohio's standby rates is the design of the generation and transmission demand charges. Specifically the demand charge, with its menu of FORs, is complex and places substantial risk on the standby customer to accurately forecast its generating unit outage rate. The risk to the customer is created primarily by the fact that under forecasting the actual unit outage rate can lead to a substantial cost penalty when the customer is billed under the applicable supplemental rate schedule. At the same time, over forecasting actual unit performance forces the customer to pay generation and transmission demand charges in excess of the amount actually required to back up the customer's generating unit in a given year.

AEP Ohio's standby tariffs also lack adequate price signals that could provide incentives to standby customers to improve the operation of their own generating units or to make more efficient use of local utility resources. For example, the tariffs do not incorporate daily generation demand charges that would give standby customers an incentive to reduce the duration of their generating unit outages. In addition, the generation demand charges and fuel charges lack time-ofuse price signals that would encourage customers to shift their use of the utility's resources to off-peak periods that exhibit a lower marginal cost of service.

Furthermore, the standby charges for the use of AEP Ohio's shared distribution facilities fail to recognize load diversity.

Finally, AEP Ohio's standby tariffs do not provide the standby customer with adequate flexibility to meet its standby requirements through alternative means such as self-dispatch, competitive market purchases, or special contracts.

Possible remedies for these issues are set forth below.

\section{Potential Modifications to Standby Tariffs}

Following are suggested modifications to AEP Ohio's standby tariffs for consideration:

\section{For customers who take standby generation} service from the utility, the monthly backup charge (reservation demand charge) for standby generation service should be set such that it is equivalent to the best FOR exhibited by any generating unit on AEP Ohio's system. This standby generation charge can be calculated by multiplying the best FOR by the demand charge in the customer's otherwise applicable fullrequirements tariff. For example, using the demand charge in the Columbus Southern Power rate zone, General Service Medium Load Factor (Schedule GS 3) rate schedule, and an assumed FOR of 5 percent produces a monthly generation reservation charge of $\$ 0.483 / \mathrm{kW}(0.05 \times \$ 9.662 / \mathrm{kW}) .{ }^{16}$

2. Daily standby generation demand charges should be assessed to provide incentives to improve the performance of self-generating units. In addition to the reservation demand charge discussed previously, standby customers should pay daily demand charges when they actually take backup power from the utility. The daily demand charge is the demand charge as specified in the

16 In September 2012, the generation demand charges for Columbus Southern Power Rate Zone were modified as follows: Schedule GS-3 (secondary voltage) - $\$ 10.867 / \mathrm{kW}$, Schedule GS-3 (primary voltage) - \$10.511/kW. 
appropriate full-service tariff adjusted to exclude the standby portion, divided by the average number of billing days in a month. When purchasing maintenance power, the daily demand charges should be reduced to reflect the scheduling of maintenance power when costs and systems stresses are low. The standby customer also should pay the utility's applicable fuel and purchased power charges as well as all other applicable riders.

3. Customer-generators should have the option to buy backup power from the market through the utility and thereby avoid the monthly reservation charge for standby generation service. Under this alternative approach, the standby customer would purchase backup energy from the utility only on an as-needed basis. Such purchases would be priced at the real time locational market price applicable to the geographic location at which the customer takes service. In addition, the customer would pay a share of any contracted capacity purchased, an allocated portion of transmission costs and ancillary services, and a small administrative fee to cover the utility's procurement cost if the power is purchased through the utility.

4. Customer-generators should have the option to provide the utility with a load reduction plan that demonstrates their ability to reduce a specified $\mathrm{kW}$ amount of load within a required timeframe to mitigate all or a portion of backup demand charges. This alternative approach would establish the standby customer's generation reservation demand charge as a function of the load that the local utility would be required to meet through standby service. This standby service amount would be less than the rated output of the customer's self-generating unit because it would incorporate an adjustment for the amount of load reduction that the customer can achieve. This option would give the standby customer the flexibility to use demand response to meet all or a portion of its needs. The local utility would retain the discretion to approve each standby customer's load reduction plan, including whether the customer can shed load with a sufficient response time that would allow the utility to avoid generation reserve costs in accordance with the utility's applicable reliability criteria. This assumes that the utility is providing the backup service.
5. Standby charges for shared distribution facilities should reflect the load diversity of CHP customers. Under AEP Ohio's tariffs today, customer generators taking secondary or primary voltage level service pay the same distribution charges as full-requirements customers. This rate design is appropriate for distribution facilities dedicated entirely to serving the standby customer. However, charges for shared distribution facilities, such as substations and primary feeders, should reflect load diversity. Load diversity recognizes that a given portion of the distribution system is not specifically designed to meet a single customer's needs, but is instead designed to serve the coincident peak demand for distribution services that is established by a pool of customers. Load diversity can be recognized by designing the distribution demand charges on a coincident peak demand basis or by assessing charges for shared distribution facilities based on the demand established by the standby customer only during on-peak hours, as discussed below.

It should be noted that Ohio Power Company currently appears to reflect load diversity in its transmission service charges for standby customers. Specifically the customer generator pays for transmission service provided by the utility based on the selected FOR of the customer's generating unit.

6. Standby demand charges for generation and distribution service should apply only during on-peak hours. Ohio Power Company currently offers optional time-of-day schedules that assess demand charges based only on the peak demand established by the customer during on-peak hours. This provision could be applied to the determination of standby generation and distribution demand charges as well. This rate design would provide standby customers with an incentive to shift their use of the utility's assets to off-peak hours, when the marginal cost of providing service is typically much lower.

\section{Standby rate design should avoid demand} ratchets. For example, no demand ratchets should apply to AEP Ohio's charges to standby customers for shared distribution facilities. Instead customer-generators should pay for non-dedicated distribution facilities only when they are actually purchasing backup or maintenance power in a particular month. Any demand that a customer 
generator imposes on the utility system in a given month should not be used to establish that customer's distribution or other demand charges for future months.

8. Standby tariffs should be concise and easily understandable. Customers who may consider installing a cogeneration system will have a difficult time understanding all of the charges they may pay under various circumstances with the standby tariffs and riders that AEP Ohio has in place today. To reduce the complexity of the standby tariffs, the Public Utilities Commission of Ohio may wish to consider replacing the existing menu of standby generation demand charges linked to various FOR levels with a single generation standby demand charge that is designed as a function of the best FOR among generating units on the utility's system.

\section{Fuel and purchased power charges for standby} customers should vary by time of use. Standby customers have some flexibility in the scheduling of maintenance outages of their generating units. If a customer purchases maintenance power, the economic choice may be to schedule such outages during time periods when the utility's incremental cost of fuel is low. By sending a price signal that more accurately reflects the utility's marginal fuel cost, time-of-use fuel charges can assist standby customers in efficiently scheduling maintenance outages of their generating units at times that would minimize the utility's cost of providing standby (maintenance) energy. The potential benefits of time-of-use fuel charges also would apply to full service customers who are capable of shifting load to low-cost periods.

\section{Standby tariffs should specify the} circumstances under which special contracts may be warranted. Customers who have standby power requirements in excess of $50,000 \mathrm{~kW}$, as well as standby customers who have specific needs or operating conditions, may require special contracts for standby power. AEP Ohio's standby tariffs should therefore contain provisions that would allow standby customers who demonstrate unique requirements to negotiate customer-specific standby service contracts with the utility. These customerspecific contracts would be submitted to the Public Utilities Commission for review and approval, subject to appropriate confidentiality restrictions that may be required to protect the customer's commercially sensitive information.

\section{Economic Analysis of Standby Tariffs}

An economic analysis was performed to estimate the monthly costs incurred by Ohio Power Company customers who have on-site generation for both Schedule SBS and Schedule OAD SBS. To calculate these costs, an economic model was developed that estimates the monthly costs for standby, maintenance service, backup service, and supplemental power. Attachment Ohio-1, available online, describes the model in detail.

The economic analysis calculated costs for three load sizes for both the Columbus Southern rate zone and the Ohio Power rate zone. Following are the load sizes and customer generation parameters analyzed:

\section{Small Load}
a. Total Demand: 1,500 kW at 70-percent load factor
b. Customer Generation Demand: $700 \mathrm{~kW}$ at 100-percent load factor
c. Forced Outage Hours: 146
d. Maintenance Hours: 73
e. Supplemental Service on Schedule GS-3 at Primary Voltage

\section{Medium Load}
a. Total Demand: 6,000 kW at 80-percent load factor
b. Customer Generation Demand: 4,000 kW at 100-percent load factor
c. Forced Outage Hours: 73
d. Maintenance Hours: 73
e. Supplemental Service on Schedule GS-3 at Primary Voltage

\section{Large Load}
a. Total Demand: 30,000 kW at 75-percent load factor
b. Customer Generation Demand: 20,000 kW at 100-percent load factor
c. Forced Outage (Backup Service) Hours: 37
d. Maintenance Hours: 37
e. Supplemental Service on Schedule GS-4 at Transmission Voltage for the Columbus Southern rate zone and Schedule GS-3 for the Ohio Power rate zone

Attachment Ohio-2 summarizes costs at the existing tariffs for each rate zone. A comparison should not be made between the full service costs and the open access costs, because the market energy costs used for the open access tariff analysis do not incorporate all of the cost components that a customer may actually incur. BAI used historic market prices to simulate the cost of competitive 
market purchases.

In addition, an economic analysis was performed to estimate the bill impacts of the suggested tariff improvements described previously. Modeled tariff charges used to develop these bill impacts are not based on a formal cost-of-service study. Rather, the rate assumptions used in the economic model were developed by relying on the charges found in the current utility rate schedules and the transmission rider, with appropriate adjustments based on the judgment of the study authors. The modeled tariff charges included the following:

1. A generation reservation charge was developed to reflect the performance of the best generating unit on the utility's system. The reservation charge was assumed to be five percent of the applicable generation demand charge as specified in an appropriate supplemental tariff. Because we propose a uniform reservation charge for all customer generators, the model does not select a forecasted FOR.

2. A daily backup demand charge for power purchased during forced outages was developed by prorating the generation demand charge in the fullrequirements tariff. If the self-generating unit was out of service for a full month, the charges would be equivalent to the applicable full service tariff.

3. The daily maintenance demand charges were set at 50 percent of the backup charges. The maintenance costs represent a discount from the daily backup demand charges because maintenance outages must be prescheduled with the utility during periods when the utility's marginal cost of service is low. A 50-percent discount factor was therefore applied to the backup charges to recognize the lower cost of service associated with maintenance power.

4. The distribution rates were adjusted to reflect load diversity. First, the distribution reservation charge was adjusted to include only the costs associated with dedicated distribution facilities. The non-dedicated distribution costs were recovered through the daily demand charges described earlier. Second, the standby distribution reservation charges contained in the standby tariffs for each rate zone were reduced by 20 percent to estimate the dedicated distribution charge.

Attachment Ohio-3 compares the charges/rates and costs that would be incurred under the existing standby tariff charges and the proposed modifications. For Schedule SBS, only changes in standby tariff and transmission charges are shown. The calculations exclude all energy-related costs associated with purchases of fuel, supplemental power, and power purchased from competitive electricity suppliers. With the exception of the transmission rider, the calculations also exclude costs associated with all utility riders. These rider costs were excluded from the analysis because they represent a small portion of the total cost of providing service to the customer. Moreover, none of the standby tariff modifications proposed in this study affects these rider charges.

Attachment Ohio-3, page 1, shows the results of the economic analysis for the Columbus Southern rate zone for Schedule SBS. Page 2 of the same attachment shows the results of the economic analysis for rate Schedule SBS for the Ohio Power rate zone.

The analysis for both of the rate zones indicates a slight reduction in cost for the suggested modifications for small load and medium load customers. The economic analysis for the large load indicates an increase in the cost associated with the modifications to Schedule SBS.

However, the small and medium load economic analyses model a worst-case scenario. That is, for each FOR, the maximum backup energy and arguably the maximum number of backup days were selected.

For example, for the small load the model assumes that the customer selected a FOR of 20 percent under the existing standby tariff rate design. This assumption implies that backup power would be needed for seven days [(730 hours x 20\%)/24] and the amount of backup energy would be $102,200 \mathrm{kWh}(700 \mathrm{~kW}$ x 730 x 20\%). This reflects the maximum amount of backup energy required and likely the maximum backup days. It is highly unlikely that a customer would pick a FOR assuming charges for the maximum amount of backup hours and backup energy. Of note, if the customer exceeds during the year the maximum specified hours for backup power, the customer will default to the supplemental rate. For the small load example, this would increase the generation charge to approximately $\$ 9.662$ per $\mathrm{kW}$. This is an increase from the $\$ 3.171$ per $\mathrm{kW}$ that the customer is currently paying.

In addition, by defaulting to the supplemental rate, the transmission cost would increase from $\$ 0.50$ per $\mathrm{kW}$ to $\$ 2.005$ per $\mathrm{kW}$. Because of the significant penalties involved, it is highly likely that the customer would overforecast the FOR for its generating unit.

This is significant because the analysis shows that under the current Schedule SBS the customer incurs the bulk of its charges through standby demand charges that the customer must pay each month, regardless of actual 
use of standby service. However, when the tariff schedule is modified to incorporate the rate changes recommended in this study, a significant portion of the charges are incurred through the daily demand charges, which are assessed only when backup or maintenance power is actually purchased by the customer.

For the large load customer, the analysis is affected by the selected FOR under the existing standby tariff charges. Had a higher FOR such as 20 percent been selected, the economic analysis would have indicated that the tariff modifications proposed in this study would result in lower costs to the customer. Finally, it should be noted that Schedule SBS may cease to exist by the end of 2015, as Ohio Power Company is expected to transition to full open access at that time.

In addition to the economic analysis for Schedule SBS discussed earlier, the study also provides an analysis that compares the economic impact of the current Schedule OAD-SBS tariffs to the tariff charges that would result from the rate modifications proposed in this study. In this instance, only the distribution charge changes. For Schedule OAD SBS, the only suggested revision is to reflect load diversity in the distribution reservation demand charges. As discussed earlier in this chapter, this rate modification is appropriate because the distribution reservation demand charges should only reflect the cost of those facilities that are dedicated to serve the customer. As was the case in the analysis of the Schedule SBS rates, this tariff modification was reflected in the tariff charges by reducing the distribution costs by 20 percent. This adjusted portion of the distribution costs was then added to the daily demand charge that is paid when the customer purchases backup or maintenance power.

Under Schedule OAD-SBS, the customer purchases maintenance power not from Ohio Power Company but through a third-party supplier. This largely eliminates the utility cost savings that could be realized by scheduling maintenance power during off-peak periods. For this reason, the study assumes that the charges for backup and maintenance distribution service would be identical under this schedule.

Attachment Ohio-4 shows that the tariff modifications proposed in this study would result in lower Schedule OAD-SBS costs in each of the rate zones for both the small and medium loads. The large load customer would incur no distribution costs because it is assumed that this customer purchases power at a transmission voltage level delivery point. The large customer would be securing standby generation from the competitive market and procuring transmission service under the applicable FERC OATT. Consequently the tariff modifications proposed in this study would have no impact on the cost of standby service for the large customer.

It is important to note that customers taking standby service on an interruptible basis would avoid both the utility's standby reservation charges and backup charges associated with any unscheduled outages. (The customer would still be required to pay for any dedicated distribution facilities.) However, the customer would default to the full-requirements tariff, and pay the generation, transmission, and distribution charges in that tariff, if the customer is unable to interrupt its load in compliance with the standby tariff conditions. 


\section{Chapter 7. Utah \\ Standby Rates for Customers of Rocky Mountain Power}

\section{Description of Standby Rates}

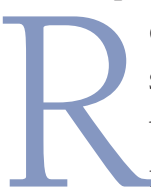

ocky Mountain Power (RMP) offers standby service on Schedule 31 to customers who use their own generating equipment on a regular basis. Total backup and maintenance power taken by the customer under Schedule 31 cannot exceed 10,000 kW. The schedule contains rates, terms, and conditions for the provision of backup power, maintenance power, and excess power:

1. Backup power is the electric energy and capacity supplied by RMP during an unscheduled outage of the customer's electric generating equipment. The backup demand is measured only during the on-peak hours, 7 a.m. to 11 p.m. Monday through Friday, except designated holidays and days when generator maintenance is scheduled. All energy is priced under the provisions of the applicable general service schedule.

2. Maintenance power is the electric energy and capacity supplied by RMP during scheduled outages of the customer's generating equipment. For customers who have a peak demand in excess of 1,000 kW, the customer must submit a proposed maintenance schedule for each month of an 18-month period. The customer can schedule maintenance for a maximum of 30 days per year. The 30 days may be taken in either one continuous period or two continuous 15-day periods.

3. Excess power is the power that RMP supplies to the customer in excess of the total contract demand. The total contract demand is defined as the sum of the supplementary contract demand and the backup contract demand. Supplemental power is billed and priced pursuant to the provisions of the applicable general service schedule.

\section{Description of Rate Components}

Schedule 31 contains four charges that vary by voltage level (secondary, primary, and transmission):
1. Monthly customer charges

2. Facilities charges

3. Daily on-peak backup power charges - the daily maintenance power charges are set at one-half of the backup power on-peak charges

4. Excess power charges

Schedule 31 does not contain a generation reservation charge. The facilities charges apply to the $\mathrm{kW}$ of backup contract demand and are designed to recover the cost of distribution and transmission facilities.

The backup power charges apply only during the onpeak time periods designated in Schedule 31. No backup power charges are assessed to customers during off-peak hours. All backup and maintenance energy used by the customer is billed under the pricing provisions of the applicable general service schedule.

The excess power charges in Schedule 31 are set at approximately $\$ 40$ per $\mathrm{kW}$ for primary and transmission voltage customers. The excess power charges apply only to demand that exceeds the total contract demand. These charges are intended to provide customers with an incentive to accurately designate their backup contract demand and supplemental power demand.

\section{Description of Rider Schedule 33}

RMP also offers Generation Replacement Service (Schedule 33). Schedule 33 is available to customers who wish to curtail on-site generation and receive replacement power and energy from RMP. RMP offers the customer terms and conditions associated with the provision of generation replacement service at least five days in advance. The customer must respond to RMP's offer within 48 hours. If the offer is accepted, the customer then contracts for a specific amount of replacement power and energy at a designated price for the offer period. The customer must pay for the contracted amount of replacement power regardless of the customer's actual use of replacement service. 


\section{Assessment of Standby Rates}

Schedule 31 facilities charges do not recognize load diversity in the use of RMP's shared transmission and distribution facilities.

In addition, Schedule 31 does not provide the standby customer with adequate flexibility to meet its standby requirements through alternative means such as selfdispatch, market-priced power purchases for backup power, or special contracts.

\section{Potential Modifications to Standby Tariff}

Following are suggested modifications to RMP's standby tariffs for consideration:

\section{The on-peak, backup power charges should} be stated on a seasonal basis. Although energy charges for supplemental-service rate schedules differentiate power charges for the summer and non-summer periods, backup power charges do not. The backup power charges should reflect higher rates during the summer period and lower rates during the non-summer period consistent with the supplemental power rates.

2. Customer-generators should have the option to buy backup power from the utility at market prices and thereby avoid the backup charge for standby generation service. Under this approach, the standby customer would purchase backup capacity and energy from the utility only on an as-needed basis. Such purchases would be priced at market prices at the appropriate trading hub. In addition, the customer would pay a share of any transmission and ancillary services costs, as well as a small administrative fee to cover the utility's procurement cost.

RMP's Energy Exchange Program Rider (Schedule 71) provides payments to participating customers at market-based prices for voluntarily reducing electricity consumption when called upon by the utility. The same data source for these hourly market prices could be used to price backup and maintenance energy under a market supply option for standby service.

3. Customer-generators should have the option to provide the utility with a load reduction plan that demonstrates their ability to reduce a specified amount of load ( $\mathrm{kW}$ ) within a required timeframe to mitigate all, or a portion of, backup demand charges. This approach would establish the standby customer's backup demand as a function of the load that the local utility would be required to meet through standby service. The standby service amount would be less than the rated output of the customer's selfgenerating unit because it would incorporate an adjustment for the amount of load reduction the customer can achieve. This option would give the standby customer the flexibility to use demand response to meet all, or a portion of, its needs. The utility would retain the discretion to approve each standby customer's load reduction plan, including whether the customer can shed load with a sufficient response time that would allow the utility to avoid generation costs in accordance with applicable reliability criteria.

4. Standby demand charges for shared transmission and distribution facilities should reflect the load diversity. The rates for shared transmission and distribution facilities, such as substations and primary feeders, should reflect load diversity. Load diversity recognizes that the transmission and a portion of the distribution systems are not specifically designed to meet a single customer's needs but are instead designed to serve the coincident peak demand for transmission and distribution services established by a pool of customers.

5. The cap for the provision of backup and maintenance service should be raised. RMP's Schedule 31 restricts the provision of backup and maintenance power to loads that do not exceed $10,000 \mathrm{~kW}$. A load cap may be needed to address concerns regarding the adequacy of the utility's generation reserves. However, the level of the cap is low and therefore unnecessarily restrictive.

6. Standby tariffs should specify the circumstances under which special contracts may be warranted. Customers who have specific needs or operating conditions may require special contracts for standby power. For example, RMP should be required to negotiate a special contract for the provision of standby service with any customer whose backup generation requirement exceeds the designated cap. RMP's standby tariffs should contain provisions that would allow standby customers who demonstrate unique requirements to negotiate customer-specific standby service contracts with the utility. These customer-specific contracts would be submitted to the Public Service Commission for review and approval, subject to appropriate confidentiality restrictions that may be required to protect the customer's commercially sensitive information. 


\section{The customer should be able to use the 30-} day allotment of maintenance power over more than two instances per year. Schedule 31 allows the standby customer to take maintenance power either in one continuous 30-day period or two continuous 15-day periods. Allowing more flexibility on the number of times a customer can take maintenance power would provide more opportunities to address generator reliability issues.

\section{Economic Analysis of Potential Modifications}

BAI performed an economic analysis to estimate the monthly costs incurred by RMP customers who have on-site generation under Schedule 31. BAI developed an economic model that estimates the monthly costs for reservation, maintenance service, backup service, and supplemental power. Attachment Utah 1, available online, describes the model results in detail.

The economic analysis calculated costs for three load sizes with the following customer generation parameters:

\section{Small Load}
a. Total Demand: 4,350 kW at 75-percent load factor
b. Customer Generation Demand: 1,950 kW at 100-percent load factor
c. Forced Outage Hours: 48
d. Maintenance Hours: 72
e. Supplemental Service on Schedule Large General Service (Schedule 8) at Primary Voltage

\section{Medium Load}
a. Total Demand: 19,500 kW at 80-percent load factor
b. Customer Generation Demand: 7,500 kW at 100-percent load factor
c. Forced Outage Hours: 48
d. Maintenance Hours: 36
e. Supplemental Service on Schedule General Service - High Voltage (Schedule 9) at Transmission Voltage

\section{Large Load}
a. Total Demand: 25,000 kW at 80-percent load factor
b. Customer Generation Demand: 25,000 kW at 80-percent load factor
c. Forced Outage (Backup Service) Hours: 48
d. Maintenance Hours: 48
e. Supplemental Service on Schedule General Service - High Voltage (Schedule 9) at Transmission Voltage

Attachment Utah-2 summarizes Schedule 31 costs at the existing tariff rates for each representative load based on the output of the economic model.

In addition, BAI performed an economic analysis to estimate the bill impacts of the suggested tariff improvements described earlier in this chapter. Modeled tariff charges used to develop these bill impacts are not based on a formal cost of service study. Rather, the rate assumptions used in the economic model were developed based on charges in the current utility rate schedules, with adjustments based on the judgment of the study authors. The principal features of the modeled tariff charges include the following:

1. The on-peak backup power charges are stated on a seasonal basis, consistent with the power charges in the supplemental rate schedules.

2. A generation reservation charge was developed to reflect the performance of the best generating unit on the utility's system. For purposes of this analysis, the reservation charge was assumed to be five percent of the applicable generation and transmission demand charges.

3. The distribution rates were adjusted to reflect load diversity. The distribution component of the reservation charge was adjusted to include only an estimate of costs associated with dedicated distribution facilities. The non-dedicated distribution costs were recovered through the daily demand charges described earlier. Because the current charges are bundled and no distinct distribution charges are available, the distribution component of the reservation charge was estimated by the study authors.

4. The daily maintenance demand charges were set at 50 percent of the backup charges. The maintenance costs represent a discount from the daily backup demand charges because maintenance outages must be pre-scheduled with the utility during time periods when the utility's marginal cost of service is low.

Attachment Utah 3 compares the charges/rates and costs that would be incurred under the existing standby tariff charges and the modified charges. Page 1 of the attachment shows the current and proposed facilities and backup power charges for primary and transmission 
voltage customers. The calculations used to develop the graphs on page 2 of the attachment exclude all energyrelated supplemental power and rider costs.

As shown on Attachment Utah-3, BAI developed a backup power reservation charge to reflect the estimated performance of the best self-generating unit on the utility's system, and the facilities charges were revised to reflect load diversity. The charges are estimates and were not developed from a cost-of-service study.

Page 2 of Attachment Utah-3 shows that the creation of seasonal backup power charges result in higher costs during the summer months and lower costs in the winter months. In addition, the revised charges are lower because of the reduction to the facilities charges to reflect load diversity for shared transmission and distribution facilities.

It is important to note that customers taking standby service on an interruptible basis would avoid both the utility's standby reservation charges and backup charges associated with any unscheduled outages. (The customer would still be required to pay for any dedicated distribution facilities.) However, the customer would default to the full-requirements tariff, and pay the generation, transmission, and distribution charges in that tariff, if the customer is unable to interrupt its load in compliance with the standby tariff conditions. 


\section{References}

Johnston, L., Takahashi, K., Weston, F., and Murray, C. (2008). Rate Structures for Customers with Onsite Generation: Practice and Innovation. California Energy Commission, PIER Energy Systems Integration Program. CEC-500-2008059. National Renewable Energy Laboratory, Golden, CO. Available at: http://www.energy.ca.gov/2008publications/ CEC-500-2008-058/CEC-500-2008-058.PDF.

Lazar, J. (2013). Rate Design Where Advanced Metering Infrastructure Has Not Been Fully Deployed. Montpelier, VT: Regulatory Assistance Project. Available at: http://www. raponline.org/document/download/id/6516.

Stanton, T. (2012). Electric Utility Standby Rates: Updates for Today and Tomorrow. Silver Spring, MD: National Regulatory Research Institute. Available at: http://www. nrri.org/documents/317330/94c186ab-4f16-4a69-8e8cece658e752bl.
Weston, F., Bluestein, J., Hedman, B., Hite, R. (2009). Standby Rates for Customer-Sited Resources: Issues, Considerations and the Elements of Model Tariffs. The Regulatory Assistance Project, Montpelier, VT. Available at: http://www.epa. gov/chp/documents/standby_rates.pdf.

The White House, Office of the Press Secretary (2012) President Obama Signs Executive Order Promoting Industrial Energy Efficiency. [press release]. Retrieved from: http:// www.whitehouse.gov/the-press-office/2012/08/30/president-obama-signs-executive-order-promoting-industrialenergy-effici 


\section{Attachments}

\section{Attachment Arkansas-1}

Standby Rate Model Description

\section{Attachment Arkansas-2}

Costs at Existing Standby Rates

\section{Attachment Arkansas-3}

Cost Comparison of Existing Rates and Modified Rates

\section{Attachment Colorado-1}

Standby Rate Model Description

\section{Attachment Colorado-2}

Costs at Existing Standby Rates

\section{Attachment Colorado-3}

Cost Comparison of Existing Rates and Modified Rates

\section{Attachment New Jersey-1}

Standby Rate Model Description

\section{Attachment New Jersey-2}

Costs at Existing Standby Rates

\section{Attachment New Jersey-3}

Cost Comparison of Existing Rates and Modified Rates

\section{Attachment Ohio-1}

Standby Rate Model Description

Attachment Ohio-2

Costs at Existing Standby Rates

\section{Attachment Ohio-3}

Cost Comparison of Existing Rates and Modified Rates (Columbus Southern Zone)

\section{Attachment Ohio-4}

Cost Comparison of Existing Rates and Modified Rates

(Ohio Power Zone)

\section{Attachment Utah-1}

Standby Rate Model Description

\section{Attachment Utah-2}

Costs at Existing Standby Rates

\section{Attachment Utah-3}

Cost Comparison of Existing Rates and Modified Rates 
The Regulatory Assistance Project (RAP) is a global, non-profit team of experts focused on the long-term economic and environmental sustainability of the power and natural gas sectors. We provide technical and policy assistance on regulatory and market policies that promote economic efficiency, environmental protection, system reliability, and the fair allocation of system benefits among consumers. We work extensively in the US, China, the European Union, and India.

Visit our website at www.raponline.org to learn more about our work. 


\section{$/$ The Regulatory Assistance Project}

Beijing, China • Berlin, Germany • Brussels, Belgium Montpelier, Vermont USA • New Delhi, India

50 State Street, Suite 3

Montpelier, Vermont 05602

802-223-8199

www.raponline.org 